\title{
Land Surface Temperature Trend and Its Drivers in East Africa
}

\section{Abera, Temesgen}

2020-12-16

Abera , T , Pellikka , P , Heiskanen , J \& Maeda, E 2020 , ' Land Surface Temperature

Trend and Its Drivers in East Africa ', Journal of Geophysical Research : Atmospheres, vol.

125 , no. 23 , ARTN e2020JD033446 . https://doi.org/10.1029/2020JD033446

http://hdl.handle.net/10138/327453

https://doi.org/10.1029/2020JD033446

acceptedVersion

Downloaded from Helda, University of Helsinki institutional repository.

This is an electronic reprint of the original article.

This reprint may differ from the original in pagination and typographic detail.

Please cite the original version. 


\title{
Land surface temperature trend and its drivers in East Africa
}

\author{
Temesgen Alemayehu Abera ${ }^{* *, 2}$, Janne Heiskanen ${ }^{1,2}$, Eduardo Eiji Maeda ${ }^{1}$, Petri K. E. Pellikka ${ }^{1,2}$ \\ ${ }^{1}$ Department of Geosciences and Geography, P.O. Box 68, FI-00014 University of Helsinki, Finland \\ ${ }^{2}$ Institute for Atmospheric and Earth System Research, Faculty of Science, University of Helsinki, \\ Finland
}

Corresponding author: Temesgen Abera (temesgen.abera@ helsinki.fi)

\begin{abstract}
Land surface temperature (LST) is affected by surface-atmosphere interaction. Yet, the degree to which surface and atmospheric factors impact the magnitude of LST trend is not well established. Here, we used surface energy balance, boosted regression tree model, and satellite observation and reanalysis data to unravel the effects of surface factors (albedo, sensible heat, latent heat, and ground heat) as well as incoming radiation (shortwave and longwave) on LST trends in East Africa (EA). Our result showed that $11 \%$ of EA was affected by significant $(P<0.05)$ daytime annual LST trends, which exhibited both cooling of $-0.19 \mathrm{~K} \mathrm{year}^{-1}$ (mainly in South Sudan and Sudan) and warming of $0.22 \mathrm{~K} \mathrm{year}^{-1}$ (mainly in Somalia and Kenya). The nighttime LST trends affected a large part of EA $(31 \%)$ and were dominated by significant warming trend $\left(0.06 \mathrm{~K} \mathrm{year}^{-1}\right)$. Influenced by contrasting daytime and nighttime LST trends, the diurnal LST range reduced in 15\% of EA. The modeling result showed that latent heat flux (32\%), incoming longwave radiation (30\%), and shortwave radiation (23\%) were stronger in explaining daytime LST trend. The effects of surface factors were stronger in both cooling and warming trends, whereas atmospheric factors had stronger control only on surface cooling trends. These results indicate the differential control of surface and atmospheric factors on warming and cooling trends, highlighting the importance of considering both factors for accurate evaluation of the LST trends in the future.
\end{abstract}

Keywords: Land surface temperature; Trend; Surface energy balance; MODIS Aqua; MERRA-2. 


\section{Introduction}

Land surface temperature trends play a crucial role in the assessment of land-atmosphere interactions and climate change. The radiometric land surface temperature (hereinafter LST) is a key parameter in the climate system that is modulated by the exchange of heat and water between the land surface and the atmosphere from local to global scales (Liang et al., 2013; Yu et al., 2008). LST has been identified as a high-priority parameter by the International Geosphere-Biosphere Programme and an essential climate variable by Global Climate Observation System (GCOS) of the World Meteorological Organization (WMO) (GCOS, 2016).

The magnitude of LST trend is determined by surface and atmosphere interaction (Jin and Dickinson, 2010; Schmugge and Becker, 1991). Surface conditions such as vegetation type, cover, and soil moisture affect LST by regulating the amount of energy and water exchanged with the atmosphere (Peñuelas et al., 2009; Sun and Pinker, 2004; Pielke et al., 1998). Consequently, global environmental changes have direct impact on the LST trend through altering the surface vegetation dynamics. Recent studies reported greening and browning trends in East Africa and beyond (Forzieri et al., 2017; Zhu et al., 2016). While many studies reported $\mathrm{CO} 2$ fertilization as the main driver for surface greening in tropics (Zhu et al., 2016; Graven et al., 2013), some studies indicated enhanced precipitation in the drylands of sub-Saharan Africa (e.g., Brandt et al., 2017). Such vegetation trends in the region can have an impact on surface energy balance (Forzieri et al., 2020) and contribute to the LST trend.

Changes in incoming solar radiation and atmospheric longwave radiation directly affect the LST trend through their impact on energy supply (Donohoe et al., 2014). As the main source of energy to the climate system, incoming solar radiation (SRi) determines the Earth's energy cycle (Wild et al., 2014; Ohmura and Gilgen, 1993). An increase or decrease in SRi directly impacts LST trend by influencing energy supply at the Earth's surface. SRi changes can be induced by aerosol emissions and cloud cover dynamics (Pfeifroth, 2018; Wild, 2016; Liepert et al., 1994). Incoming longwave radiation (LRi) affects the LST through radiative heating of the earth's surface. Most of the outgoing longwave radiation from the surface is absorbed by the atmosphere and much of this is reradiated to warm the earth's surface. The magnitude of LRi is affected by greenhouse gas concentrations (Donohoe et al., 2014), cloud cover (Stephens \& Webster, 1981), and water vapor (Compo \& Sardeshmukh, 2009) in the atmosphere.

Regional or global monitoring of LST trend is mainly feasible using satellite observations due to scarcity of in situ observation over a wide geographic area. Spaceborne radiometers that operate in the infrared (IR) and microwave (MW) wavelengths can be used for LST trend analysis. LST estimates based on IR sensors (e.g., from Moderate Resolution Imaging Spectroradiometer or MODIS, Atmospheric Infrared Sounder or AIRS, Along-Track Scanning Radiometer or ATSR, etc.) are preferred due to their high radiometric accuracy, sensor stability, and the availability of products routinely (Smith et al., 2012; Wan et al., 2004; Aumann et al., 2019). The main drawback of IR LSTs being they are limited to clear-sky conditions.

In East Africa, where ground observations are scarce and the susceptibility to environmental changes are high (due to strong dependency of the economy and livelihood on the climate), satellite observations present a good opportunity to study LST trends. Previous studies of LST trends in EA 
or continental Africa are either: a) focused on nighttime LST trends and based on statistical analysis of sample points extracted from MODIS (Me-ead and Mc-Neil, 2019); b) inferred from global studies which are focused on a diurnal cycle and variabilities than trends (e.g., Sharifnezhadazizi, 2019; Ruzmaikin et al., 2017); c) local studies at watershed level in Tanzania (e.g., Muro et al., 2017) or d) urban-focused studies in Botswana (e.g., Akinyemi et al., 2020). Hence, comprehensive assessments of temporal and spatially explicitly LST trends (daytime, nighttime, and diurnal range) across East African landscape are currently lacking.

Furthermore, previous studies were largely focused on LST trend and the relative impact of underlying drivers to the LST trend remain unclear. Consequently, it is unknown to what extent the magnitude of LST trend is caused by changes in the land surface properties (associated with recent greening and browning trend), incoming shortwave radiation trends (related to aerosol and cloud cover dynamics), and incoming longwave radiation trends (e.g., due to changes in greenhouse gas concentration or cloud cover). Thus, it is critical to unravel whether land and atmospheric changes are mitigating or amplifying surface-warming through their influence on LST.

The objective of this study is to investigate LST trend and its drivers in East Africa from 2003 to 2018. In more detail, we examine: (1) annual and seasonal (December-February and March-May) trends of daytime, nighttime, and diurnal LST range, and 2) the impacts of surface properties (inferred from trends of latent heat flux, sensible heat flux, and albedo) as well as incoming (shortwave and longwave) radiation on annual daytime LST trend.

\section{Study area}

The study covers the East Africa (EA) region, particularly the Greater Horn of Africa (GHA) that comprises 11 countries: Burundi, Rwanda, Tanzania, Kenya, Uganda, South Sudan, Sudan, Somalia, Ethiopia, Djibouti and Eritrea (Fig. 1a). The region covers a large land area $\left(\sim 5.9 \times 10^{6} \mathrm{~km}^{2}\right)$ and is characterised by diverse topography, rainfall regimes, and vegetation types.

Climate ranges from humid ecosystems in the highlands of Ethiopia, Kenya, and Tanzania to Arid and Semi-Arid Lands (ASAL) in the lowlands of the GHA. Most parts of East Africa, especially areas close to the equator, receive bimodal rainfall that peaks in March to May ('long rains') and October to November ('short rains'). Further to north, the GHA receives unimodal rainfall that peaks in June to August (Nicholson, 2017). The annual rainfall distribution is influenced by the north-south movement of the Intertropical Convergence Zone (ITCZ). The rainfall distribution shows strong variability affected by local (e.g., topography, coasts, lakes), regional (e.g., Monsoon systems and local convergences), and remote (e.g., El Niño-Southern Oscillation, the Indian Ocean Dipole, and the Madden-Julian Oscillation, Walker Circulation) climatic factors (Nicholson, 2017; Ogallo, 1988; Indeje et al., 2000).

Associated with the heterogeneous topographic and climatic gradients, the annual average temperature varies considerably (Fig. 1b). The annual average air temperature, calculated from Modern-Era Retrospective analysis for Research and Applications (MERRA-2) data, ranges from $285 \mathrm{~K}$ in the montane forest to $307 \mathrm{~K}$ in the Danakil Depression ( -125 m b.s.l) in Ethiopia. While the corresponding LST from MODIS data ranges from $289 \mathrm{~K}$ to $328 \mathrm{~K}$ (Fig. 1c). Field measurements 
in this region (e.g., in Taita Taveta county in Kenya) further showed important control of altitude and canopy cover on the magnitude of LST (Aalto, 2020).
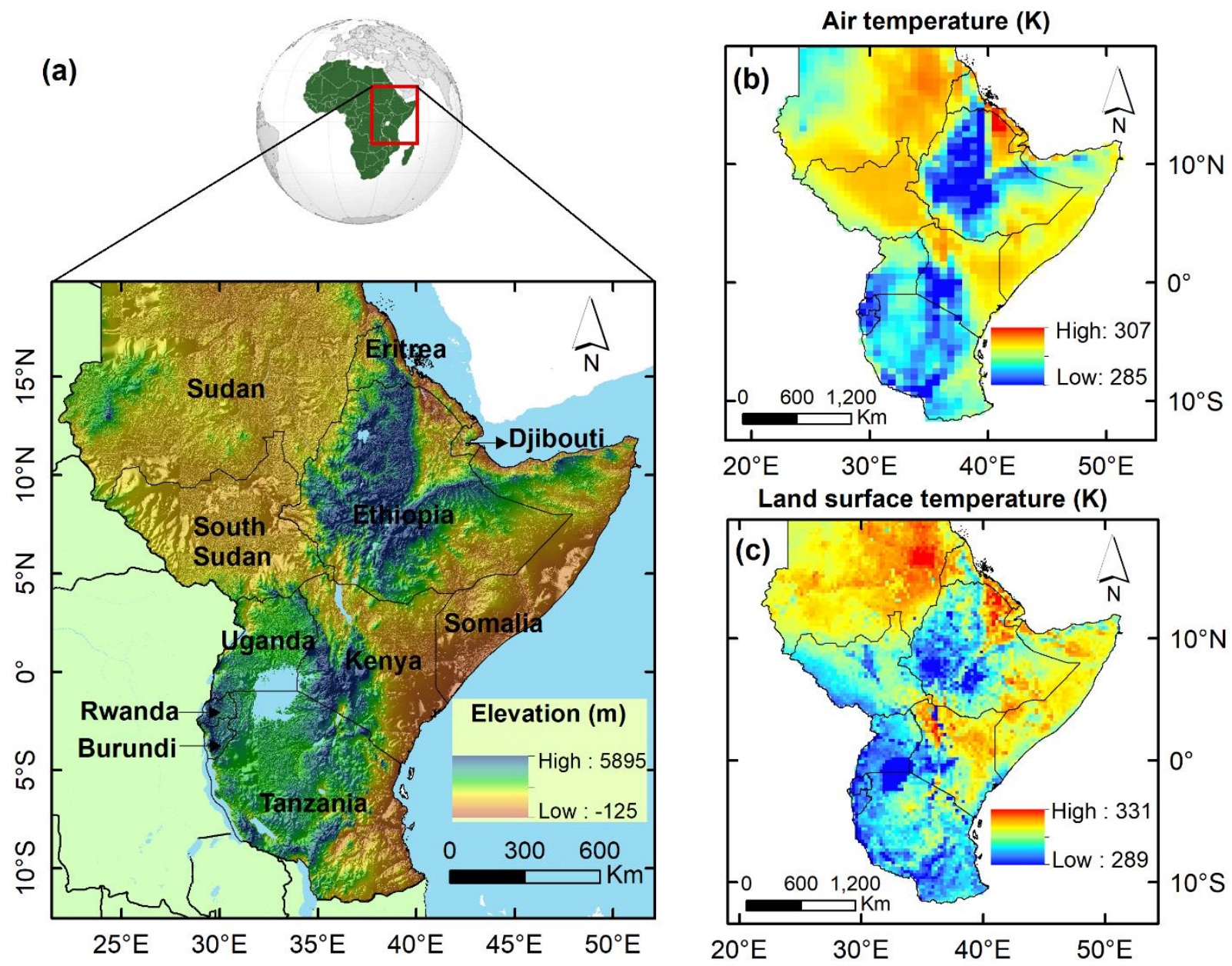

Figure 1. (a) Location of the study area with background elevation from GTOPO30, (b) 2003-2018 annual average air temperature from MERRA-2, and (c) 2003-2018 clear-sky annual average daytime land surface temperature from MODIS Aqua.

\section{Data}

LST data were obtained from the MYD11A2 product, version 6, which is derived from the MODIS sensor, onboard the Aqua satellite. This product provides LST estimates at day (1:30 pm) and night (1:30 am) overpass times. The data were downloaded from the Land Processes Distributed Active Archive Center (LP DAAC) (Wan et al., 2015). The MYD11A2 provides an average of 8-day composite LST at $1 \mathrm{~km}$ resolution. We limited our analysis to only good quality clear-sky pixels with LST error $\leq 1 \mathrm{~K}$ using the MYD11A2 quality control (QC) layer. All pixels with LST error $>1 \mathrm{~K}$ were masked from our analysis applying QC flag bits. MODIS Aqua overpass time roughly 
corresponds to daily maximum LST, which occurs in the afternoon, and daily minimum LST, which occurs after midnight; and their difference can be used for diurnal LST range computation (Ruzmaikin et al., 2013).

For identifying surface biophysical role on LST trend, daily black-sky albedo (BSA) product at local noon (MCD43A3) and 500-m resolution was downloaded from NASA using Google Earth Engine. The product has a reported accuracy of mostly better than $5 \%$ for SZA below $70^{\circ}$ (Liu et al., 2009). We chose this product due to its close timing with the overpass of MODIS Aqua (1:30 pm). Besides, the choice of albedo types (BSA, white-sky albedo, and blue-sky albedo) does not affect our result since they are strongly correlated in this region. For comparison of albedo types, refer Abera et al. (2019).

Latent heat flux (LE) data (MOD16A2) at 500-m resolution and 8-day composite were downloaded from NASA using Google Earth Engine. This product was prepared based on the Penman-Monteith equation and used inputs from daily meteorological reanalysis data (e.g., air temperature, vapor pressure deficit, relative humidity, wind speed, and surface downward solar radiation), and remotely sensed products (e.g., leaf area index or LAI, land cover, and albedo) from MODIS. Validation against eddy flux towers in previous studies showed a mean absolute error of $0.3 \mathrm{~mm}$ day $^{-1}$ (Running et al., 2017).

Downwelling shortwave radiation (DSW) data at $0.5^{\circ} \times 0.6^{\circ}$ resolution and monthly timestep were obtained from Modern-Era Retrospective analysis for Research and Applications (MERRA-2) (https://gmao.gsfc.nasa.gov/reanalysis/MERRA-2/). Previous comparison studies against station data showed that DSW data captures radiation variabilities in our study area (Stettz et al., 2019). MERRA2 DSW data have a closer accuracy value $\left(4-7 \mathrm{Wm}^{-2}\right)$ compared with CERES EBAF data $(3-5$ $\mathrm{Wm}^{-2}$ ) (Hinkelman, 2019; Kato et al., 2018). Moreover, we used screen-level (2 m) maximum airtemperature (Tmax) data from MERRA-2 with the same spatio-temporal resolution to that of DSW. The Tmax, which closely matches with Aqua overpass time, was used to calculate downwelling longwave radiation (Eq. 4). Over land surface, Tmax from MERRA-2 reported to have a daily mean bias of $0.1 \mathrm{~K}$ and maximum bias of $1.5 \mathrm{~K}$ against in situ data (Bosilovich et al., 2015).

In addition, different reanalysis and satellite products were used for comparison and exploratory analysis. The products are: Aerosol Optical Depth (AOD) from MERRA-2 (at $0.5^{\circ} \times 0.6^{\circ}$ resolution and monthly timestep), upwelling longwave radiation from NASA CERES EBAF (Version 4.1; 1 degree; clear-sky; monthly data), rainfall data from Tropical Rainfall Measuring Mission (TRMM3B43; $0.25^{\circ}$ resolution and monthly timestep) (Goddard Earth Sciences Data and Information Services Center, GES DISC; TRMM, 2011), MODIS Collection 6 leaf area index (LAI) product from Aqua (MYD15A2H) at 500-m resolution and 8-day composite (downloaded from NASA using GEE), and nadir bidirectional reflectance distribution function (BRDF)-adjusted reflectance from MODIS daily product (MCD43C4) at $0.05^{\circ}$ resolution was downloaded from NASA Land Processes Distributed Active Archive Center (https://lpdaac.usgs.gov/products/mcd19a1v006/)

All data cover the period from 2003 to 2018 and were harmonized spatially and temporally to common spatial scale at $25 \mathrm{~km}$ resolution and monthly timestep, respectively. Spatial resampling to $25 \mathrm{~km}$ resolution was done applying bilinear interpolation. Daily and 8-day composite data were averaged to monthly value. A summary of data used is presented in Table 1 . 
Table 1. Satellite observation and reanalysis data used in this study

\begin{tabular}{|c|c|c|c|c|c|c|c|}
\hline Data & Sensor & Product & Version & $\begin{array}{l}\text { Spatial } \\
\text { resolution }\end{array}$ & $\begin{array}{l}\text { Temporal } \\
\text { resolution }\end{array}$ & Year & Accuracy \\
\hline $\begin{array}{l}\text { Land surface } \\
\text { temperature/ } \\
\text { emissivity }\end{array}$ & MODIS & MYD11A2 & 6 & $1 \mathrm{~km}$ & 8-day & $\begin{array}{l}2003- \\
2018\end{array}$ & $\begin{array}{l}\leq 1 \mathrm{~K} \\
\text { (Wan et al., 2015) }\end{array}$ \\
\hline $\begin{array}{l}\text { Leaf area } \\
\text { index }\end{array}$ & MODIS & MYD15A2H & 6 & $500 \mathrm{~m}$ & 8-day & $\begin{array}{l}2003- \\
2018\end{array}$ & $\begin{array}{l}0.55 \\
(\mathrm{Xu} \text { et al., 2018) }\end{array}$ \\
\hline Albedo & MODIS & MCD43A3 & 6 & $500 \mathrm{~m}$ & Daily & $\begin{array}{l}2003- \\
2018\end{array}$ & $\begin{array}{l}5 \% \\
\text { (Liu et al., 2009) }\end{array}$ \\
\hline $\begin{array}{l}\text { Latent heat } \\
\text { flux }\end{array}$ & MODIS & MOD16A2 & 6 & $500 \mathrm{~m}$ & 8-day & $\begin{array}{l}2003- \\
2018\end{array}$ & $\begin{array}{l}0.3 \mathrm{~mm} \text { day }^{-1} \\
\text { (Running et al., } \\
\text { 2017) }\end{array}$ \\
\hline $\begin{array}{l}\text { Upwelling } \\
\text { longwave } \\
\text { radiation }\end{array}$ & CERES & $\begin{array}{l}\text { CERES } \\
\text { EBAF }\end{array}$ & 4.1 & $1^{\circ}$ & Monthly & $\begin{array}{l}2003- \\
2018\end{array}$ & $\begin{array}{l}3 \mathrm{~W} \mathrm{~m}^{-2} \\
\text { (Kato et al., 2018) }\end{array}$ \\
\hline Rainfall & TRMM & TRMM3B43 & 7 & $0.25^{\circ}$ & Monthly & $\begin{array}{l}2003- \\
2018\end{array}$ & $\begin{array}{l}10 \% \\
\text { (Dinku et al., } \\
2007 \text { ) }\end{array}$ \\
\hline $\begin{array}{l}\text { Downwelling } \\
\text { shortwave } \\
\text { radiation }\end{array}$ & & MERRA & 2 & $0.5^{\circ} \times 0.6^{\circ}$ & Monthly & $\begin{array}{l}2003- \\
2018\end{array}$ & $\begin{array}{l}4-7 \mathrm{~W} \mathrm{~m}^{-2} \\
\text { (Hinkelman, } \\
\text { 2019) }\end{array}$ \\
\hline $\begin{array}{l}\text { Air } \\
\text { temperature }\end{array}$ & & MERRA & 2 & $0.5^{\circ} \times 0.6^{\circ}$ & Monthly & $\begin{array}{l}2003- \\
2018\end{array}$ & $\begin{array}{l}1.5 \mathrm{~K} \\
\text { (Bosilovich et al., } \\
2015 \text { ) }\end{array}$ \\
\hline $\begin{array}{l}\text { Aerosol } \\
\text { optical depth }\end{array}$ & & MERRA & 2 & $0.5^{\circ} \times 0.6^{\circ}$ & Monthly & $\begin{array}{l}2003- \\
2018\end{array}$ & $\begin{array}{l}0.159 \\
\text { (Gueymard and } \\
\text { Yang, 2020) }\end{array}$ \\
\hline $\begin{array}{l}\text { Nadir-BRDF } \\
\text { Adjusted } \\
\text { reflectance }\end{array}$ & MODIS & MCD43C4 & 6 & $0.05^{\circ}$ & Daily & $\begin{array}{l}2003- \\
2018\end{array}$ & $\begin{array}{l}5 \% \\
\text { (Liu et al., 2009) }\end{array}$ \\
\hline
\end{tabular}

\section{Methodology}

\subsection{Identifying LST trend}

LST trend was assessed using the non-parametric Mann-Kendall trend test (Mann, 1945; Kendall, 1975). Presence of monotonic annual (2003-2018) and seasonal trends were tested for daytime LST

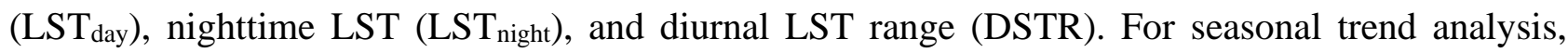
averages of major dry (DJF) and wet (MAM) seasons were used. The magnitude of trend was determined applying the non-parametric Theil-Sen estimator for every pixel (Wilcox, 1999).

\subsection{Attributing LST trend to surface biophysical and atmospheric radiation variables}

Surface biophysical and atmospheric radiation factors affecting LST trend were inferred from surface energy balance. The energy balance at the surface can be written as (Juang, 2007):

$(1-\alpha) S R_{i}+L R_{i}-\varepsilon \sigma L S T^{4}=\mathrm{LE}+\mathrm{H}+\mathrm{G}$ 
where $\alpha$ is albedo (dimensionless), SRi and LRi are incoming shortwave and longwave radiation (W $\left.\mathrm{m}^{-2}\right)$; LE is the latent heat flux $\left(\mathrm{W} \mathrm{m}^{-2}\right)$; $\mathrm{H}$ is the sensible heat flux $\left(\mathrm{W} \mathrm{m}^{-2}\right)$; $\mathrm{G}$ is the ground heat flux $\left(\mathrm{W} \mathrm{m}^{-2}\right) ; \sigma$ is the Stefan-Boltzmann constant $\left(\mathrm{W} \mathrm{m}^{-2} \mathrm{k}^{-4}\right)$; and $\varepsilon$ is the surface emissivity. Rearranging Eq. (1), the outgoing longwave radiation, which is largely a function of LST, can be given as:

$\varepsilon \sigma L S T^{4}=(1-\alpha) S R_{i}+L R_{i}-\mathrm{LE}-(\mathrm{H}+\mathrm{G})$

From Eq. (2), ignoring the impacts of surface emissivity (E), LST can be represented as a function of surface biophysical ( $\alpha, \mathrm{LE}, \mathrm{H}, \mathrm{G})$ and atmospheric radiation (SRi and LRi) variables (i.e., LST $\approx f(\alpha$, $\mathrm{LE}, \mathrm{H}, \mathrm{G}, \mathrm{SRi}, \mathrm{LRi})$ ). The contribution of the trends of each variable ( $\alpha, \mathrm{LE}, \mathrm{H}, \mathrm{G}, \mathrm{SRi}$, and LRi) to LST trend ( $\delta \mathrm{LST}$ ) was computed for every pixel using Eqs. (3) - (8) respectively, following similar approach of Forzieri et al. (2017).

$$
\begin{aligned}
& \delta L S T^{\alpha}=\frac{\partial \mathrm{LST}}{\partial \alpha} \times \delta \alpha \\
& \delta L S T^{L E}=\frac{\partial \mathrm{LST}}{\partial \mathrm{LE}} \times \delta \mathrm{LE} \\
& \delta L S T^{H}=\frac{\partial \mathrm{LST}}{\partial \mathrm{H})} \times \delta \mathrm{H} \\
& \delta L S T^{G}=\frac{\partial \mathrm{LST}}{\partial \mathrm{G}} \times \delta \mathrm{G} \\
& \delta L S T^{S R i}=\frac{\partial \mathrm{LST}}{\partial \mathrm{SRi}} \times \delta \mathrm{SRi} \\
& \delta L S T^{L R i}=\frac{\partial \mathrm{LST}}{\partial \mathrm{LRi}} \times \delta \mathrm{LRi}
\end{aligned}
$$

where $\delta$ is the trend calculated using the Theil-Sen estimator; the term $\partial \mathrm{x} / \partial \mathrm{y}$ is the sensitivity of LST to each of the surface biophysical and atmospheric radiation variables. Sensitivity term was derived from the slope of linear regression between LST and each variable. All variables were detrended prior to computing the sensitivity term.

The LRi was computed from air temperature (Ta) and air emissivity $\left(e_{a}\right)$ using Eqs. (9) and (10) (Cleugh et al., 2007). Latent heat flux (LE) was obtained from MOD16A2 data.

$$
\begin{aligned}
& L R_{i}=e_{a} \sigma T a^{4} \\
& e_{a}=(1-0.261) \times \exp \left(-7.77 \times 10^{-4} \times T a^{2}\right)
\end{aligned}
$$

The term $\mathrm{H}$ was calculated as closure of surface energy balance from net radiation (Rn), LE, and G: $H=R n-\mathrm{LE}-\mathrm{G}$

Net radiation was estimated from $\alpha, S R_{i}, e_{a}$, surface emissivity $\left(e_{s}\right)$, and $T a$ (Cleugh et al., 2007):

$R n=(1-\alpha) \times S R_{i}+\sigma \times\left(e_{a}-e_{s}\right) \times T a^{4}$

$e_{a}=(1-0.261) \times \exp \left(-7.77 \times 10^{-4} \times \mathrm{Ta}^{2}\right)$

The $e_{s}$ was computed from average of MODIS emissivity in band 29, 31, and 32, instead from band 31 and 32 only, to avoid overestimation in arid and semiarid environment (Wan et al., 2002).

Ground heat flux was estimated by multiplying the ratio of $G$ and $R n(G / R n)$ by $R n$. The G/Rn was computed from LST, $\alpha$, normalized difference vegetation index (NDVI) (Bastiaanssen, 2000): 
$\frac{G}{R n}=(L S T-273.15) \times(0.0038+0.0074 \times \alpha) \times\left(1-0.98 \times N D V I^{4}\right)$

Good quality nadir-adjusted reflectances from full inversion MODIS BRDF were retrieved using quality control layer to compute NDVI using Eq. 15.

$N D V I=\frac{N I R-R}{N I R+R}$

where NIR is the near-infrared reflectance and $\mathrm{R}$ is red reflectance.

\subsection{Boosted regression tree modelling}

The boosted regression tree (BRT) method (Elith et al., 2008) was applied to statistically measure the relative importance and contribution of the trends of each predictor variable ( $\alpha$, SRi, LRi, LE, G, and $\mathrm{H})$ to the total $\delta \mathrm{LST}$ (response variable). We used the 'dismo' package in R environment (Hijmans et al., 2017). BRT combines decision tree algorithm and boosting method to improve prediction accuracy by weighting input data prediction error in subsequent trees (Elith et al., 2008). It is nonparametric, robust to outliers and missing values, and able to explain non-linear relationships (Elith et al., 2008).

Prior to BRT modelling, spatial autocorrelation among predictor variables was checked using the variance inflation factor (VIF). The VIF of predictor variables was $<3.3$ (i.e. showed weak collinearity) and hence all variables can be used in the BRT model. The minimum predictive error was achieved using gaussian error distribution, a tree complexity of 5, a learning rate of 0.01 , bag fraction of $0.7,10$-fold cross validation, and 'fixed' tolerance method. Furthermore, only significant $(P<0.05)$ trends were used for all variables in the model.

\section{Results}

\subsection{Daytime and nighttime LST trends}

The sign and magnitude of LST trend showed high spatial variability during 2003-2018 in EA (Fig. $2 a) . \mathrm{LST}_{\text {day }}$ changed significantly $(P<0.05)$ in approximately $11 \%$ of EA $\left(787946 \mathrm{~km}^{2}\right)$. Of those, $53 \%$ of the trends were negative (cooling) at an average rate of $-0.19 \mathrm{~K}_{\text {year }}{ }^{-1}$, covering mainly the western part of EA (South Sudan, Sudan, and western Ethiopia) and western parts of Tanzania in southern EA. While the remaining $47 \%$ of the significant $\mathrm{LST}_{\text {day }}$ trend displayed positive trends (warming) at an average rate of $0.22 \mathrm{~K} \mathrm{year}^{-1}$, affecting mostly the south-eastern and the southwestern part of the study area (Somalia, southern Ethiopia, Kenya, Uganda, and eastern Tanzania).

The seasonal trends (December-February and March-May) showed a similar spatial pattern to that of the annual trends in areas of significant $(P<0.05)$ LST change (Fig. 2b and c). However, the cooling trends were more extensive in both seasons (in Sudan, South Sudan, and Ethiopia) and covered a larger area (i.e., up to $1.5 \%$ and $0.7 \%$ more areas in December-February and March-May, respectively) than the annual trends in these countries. 


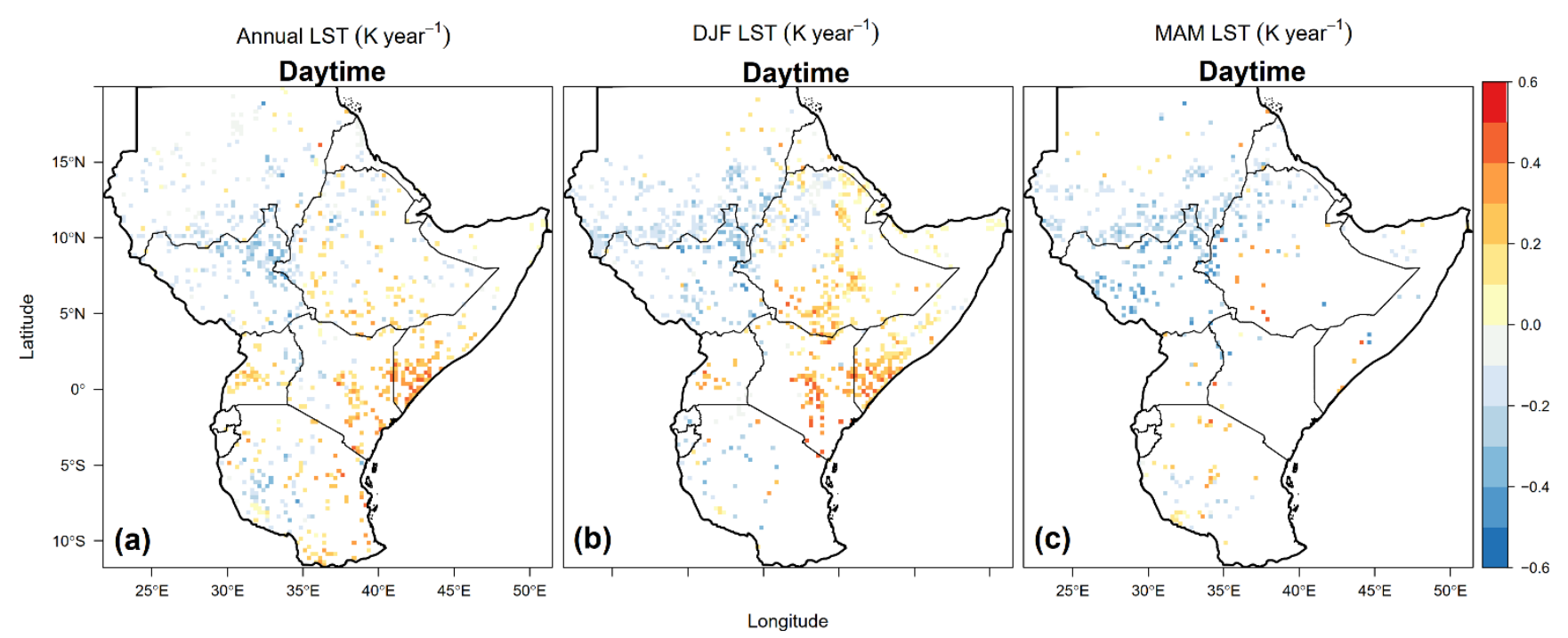

Figure 2. Spatial distribution of clear-sky (a) annual LST trend, (b) December-February LST trend, and (c) March-May LST trend during 2003-2018 in East Africa. Only statistically significant $(P<$ $0.05)$ trends are displayed.

The $\mathrm{LST}_{\text {night }}$ showed a significant $(P<0.05)$ and dominantly positive trend (warming) throughout EA (Fig. 3a-c). The trend was significant $(P<0.05)$ in 31\% of EA. From these areas $99 \%$ showed surface warming $\left(0.06 \mathrm{~K} \mathrm{year}^{-1}\right)$ and the remaining $1 \%$ displayed surface cooling of comparable magnitude $\left(-0.07 \mathrm{~K}\right.$ year $\left.^{-1}\right)$. Similarly, the seasonal LST trend showed a dominantly significant warming across EA in dry (December-February) and wet (March-May) seasons (Fig. 3b and c). Nonetheless, the total area affected by significant trend $(\mathrm{P}<0.05)$ was relatively smaller in both seasons $(17 \%$ in DJF and $13.5 \%$ in MAM) compared with the annual trend.

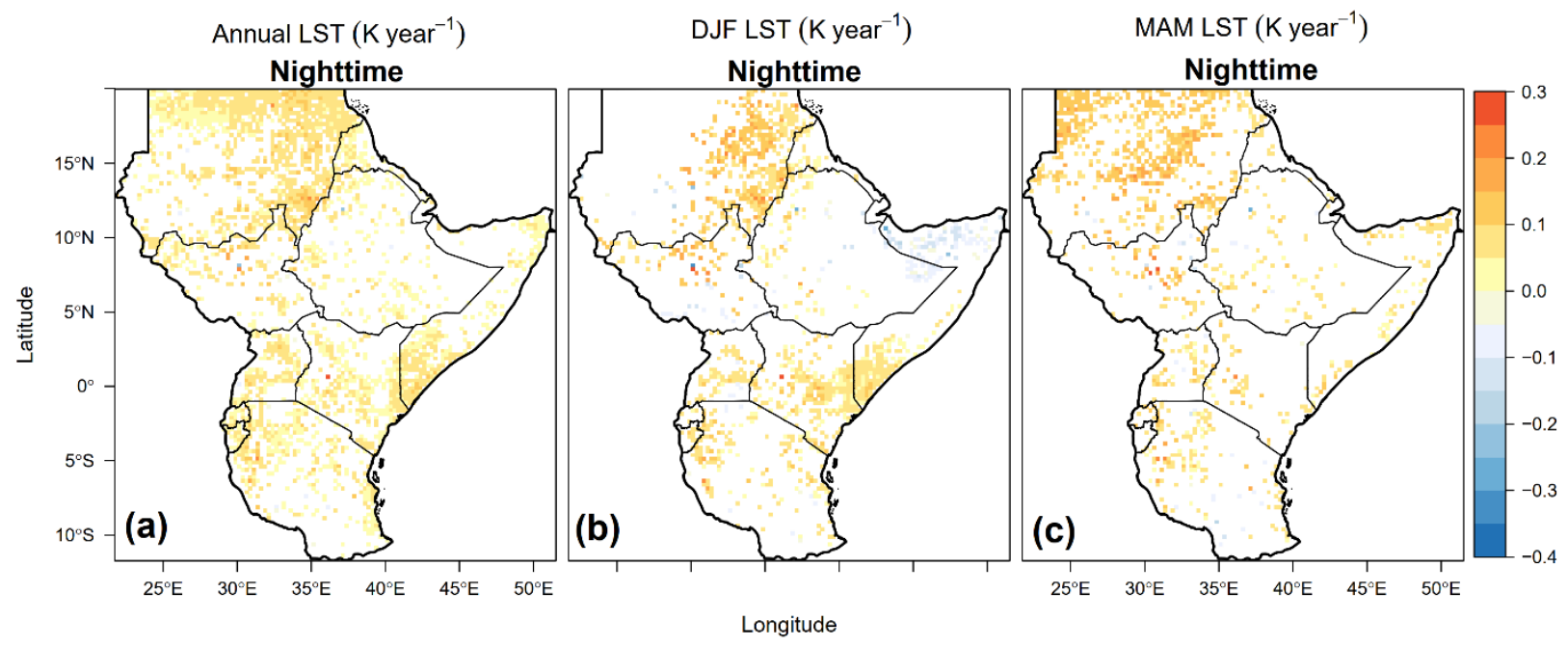

Figure 3. Spatial distribution of clear-sky nighttime (a) annual LST trend, (b) December-February LST trend, and (c) March-May LST trend during 2003-2018 in East Africa. Only statistically significant $(\mathrm{P}<0.05)$ trends are displayed.

The diurnal surface temperature range (DSTR) showed a dominantly decreasing trend across EA (Fig.4a-c). Approximately 19\% (annually), 18\% (in DJF), and 11\% (in MAM) of EA exhibited 
significant $(P<0.05)$ DSTR trend. Of this, the decreasing DSTR trend accounts for $82 \%$ annually, $88 \%$ in MAM, and $69 \%$ in DJF. The magnitude of the decreasing DSTR trend was also relatively larger annually $\left(-0.09 \mathrm{~K} \mathrm{year}^{-1}\right)$ as well as seasonally $\left(-0.13 \mathrm{~K} \mathrm{year}^{-1}\right.$ in MAM and -0.10 in $\mathrm{K}_{\text {year }}$ $\left.{ }^{1} \mathrm{DJF}\right)$ than the increasing DSTR trend $\left(0.08 \mathrm{~K} \mathrm{year}^{-1}, 0.09 \mathrm{~K} \mathrm{year}^{-1}\right.$, and $\left.0.09 \mathrm{~K} \mathrm{year}^{-1}\right)$ for the corresponding period.

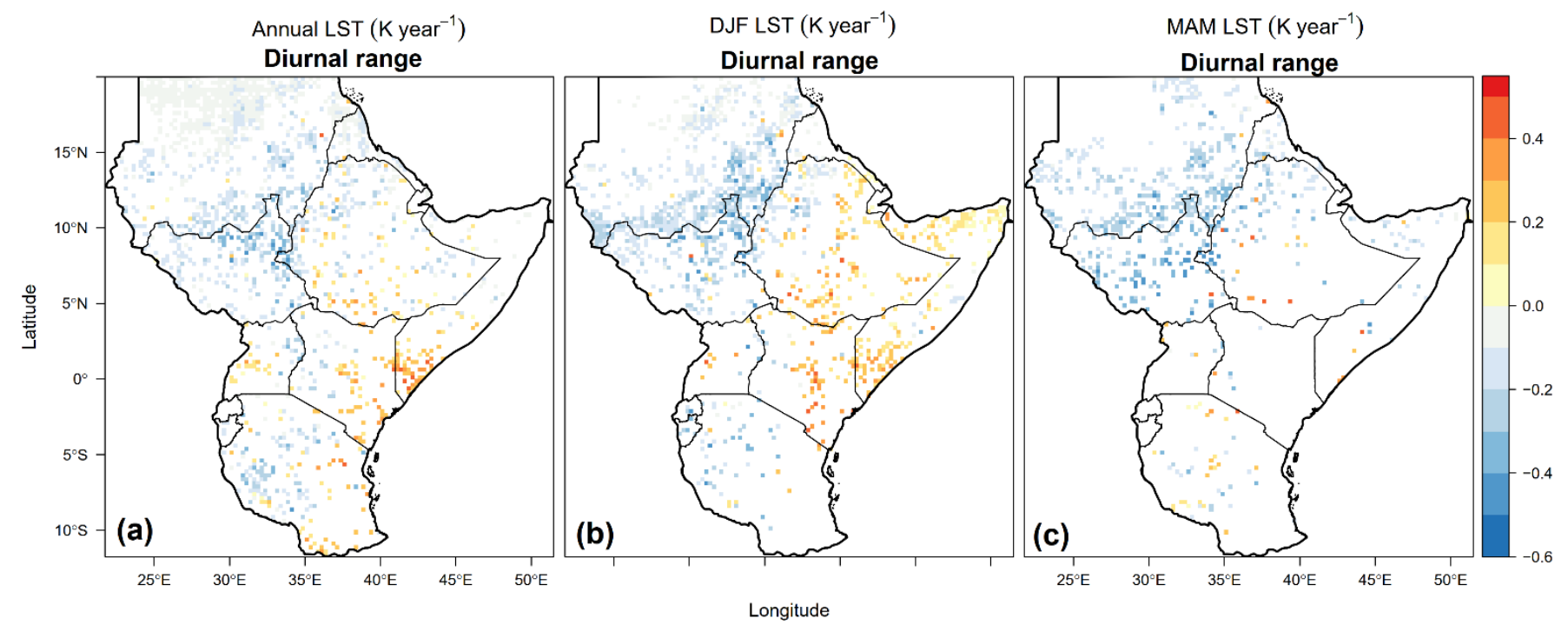

Figure 4. Spatial distribution of trends of (a) annual diurnal land surface temperature range (DSTR), (b) December-February DSTR, (c) March-May DSTR during 2003-2018 in East Africa. Only statistically significant $(\mathrm{P}<0.05)$ trends are displayed.

The spatially averaged regional annual LST trend showed different patterns for $\mathrm{LST}_{\text {day }}, \mathrm{LST}_{\text {night, }}$ and DSTR trends. Regionally, the daytime warming and cooling trends largely cancel each other and displayed a non-significant $(P>0.05)$ net cooling of negligible magnitude $\left(-0.001 \mathrm{~K} \mathrm{year}^{-1}\right)$ on average (Fig. 5a), while the regional average LST $_{\text {night }}$ and the DSTR trend were significant $(P<0.05)$ and exhibited net warming (Fig. 5b) as well as cooling (Fig. $5 \mathrm{c}$ ) of a similar magnitude $(0.003 \mathrm{~K}$ year $\left.{ }^{1}\right)$, respectively.

(a) Daytime - LST

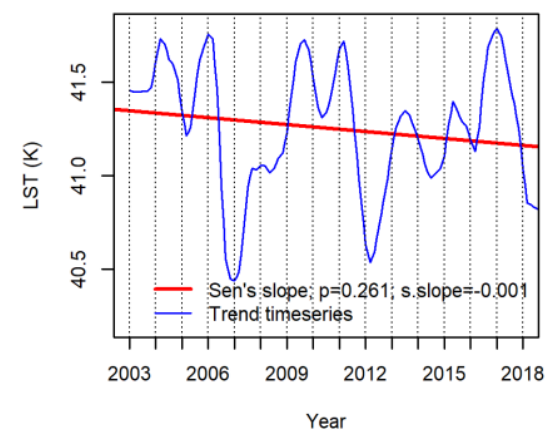

(b) Nighttime - LST

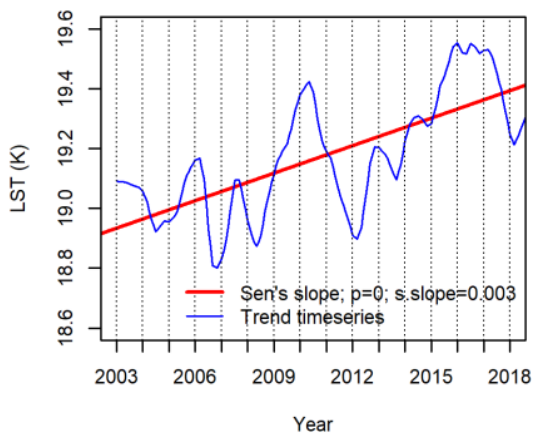

(c) Diurnal range - LST

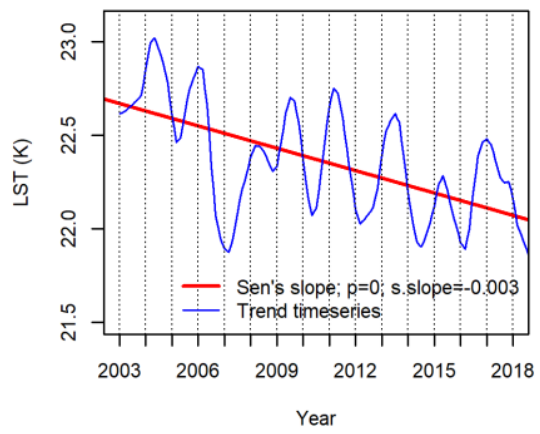

Figure 5. Regionally averaged annual daytime ( $\left.\mathrm{LST}_{\text {day }}\right)$, nighttime ( $\left.\mathrm{LST}_{\text {night }}\right)$, and diurnal (DSTR) land surface temperature trend over East Africa during 2003-2018. The red line shows the trend 
calculated using Sen's slope. The blue line shows the trend component of the LST monthly time series. Significance level determined from MK-test.

Furthermore, the latitudinal and longitudinal variations of the annual and seasonal (DJF and MAM) $\mathrm{LST}_{\text {day }}, \mathrm{LST}_{\text {night, }}$ and DSTR trends are provided in Supplementary Figs. S1, S2, and S3, respectively.

\subsection{Trends of surface biophysical and atmospheric variables}

Trends of surface biophysical and atmospheric radiation variables are displayed in Figs. 6 and 7. Albedo trends showed high spatial variability and displayed a regional average close to zero $(0.000$ \pm SD 0.001) (Fig. 6a). Similarly, in areas of significant LST warming or cooling, albedo trends were negligible and had a similar magnitude and sign $(0.001 \pm$ SD 0.001).

The SRi rather showed a dominantly decreasing trend on the average $\left(-0.894 \mathrm{Wm}^{-2}\right.$ year ${ }^{-1} \pm \mathrm{SD}$ 0.238) with trends mainly affecting the western and the southern part of EA (Fig. 5b). Regardless of the sign of LST trend, SRi showed a decreasing trend with the magnitude being higher $\left(-0.972 \mathrm{Wm}^{-}\right.$

${ }^{2}$ year $^{-1} \pm$ SD 0.711$)$ in the areas of LST cooling and relatively lower $\left(-0.228 \mathrm{Wm}^{-2}\right.$ year $^{-1} \pm \mathrm{SD}$ 0.565 ) in areas of significant LST warming (Fig. 7a, b).

Similar to the SRi trend, LRi and H showed a dominantly decreasing trend in the western and the southern part of the study area (Fig. 6c, e). Regionally, LRi decreased by $-1.116 \mathrm{Wm}^{-2}$ year $^{-1} \pm \mathrm{SD}$ 0.695 and $\mathrm{H}$ by $-1.795 \pm$ SD 0.860 . In areas of both LST warming and cooling, LRi and H showed a decreasing trend. In terms of magnitude, the LRi trend was higher $\left(-0.971 \mathrm{Wm}^{-2}\right.$ year $\left.^{-1} \pm \mathrm{SD} 0.711\right)$ than the $\mathrm{H}$ trend $\left(-0.543 \mathrm{Wm}^{-2}\right.$ year $\left.^{-1} \pm \mathrm{SD} 1.322\right)$ in pixels with LST cooling, while the opposite was true in areas of significant LST warming (Fig. 7a, b). Furthermore, G showed a dominantly decreasing trend throughout the study area (Fig. 6f). The $\mathrm{G}$ trend was smaller in magnitude in areas of LST cooling $\left(-0.167 \mathrm{Wm}^{-2}\right.$ year $^{-1} \pm$ SD 0.194$)$ than in areas of LST warming $\left(-0.315 \mathrm{Wm}^{-2}\right.$ year $^{-}$ ${ }^{1} \pm$ SD 0.151) (Fig. 7a, b).

Different from other variables, the LE trend showed a dominantly increasing and significant trend in the western and southern part of the study area (Fig. 6d). Although the LE trend increased $(0.555$ $\mathrm{Wm}^{-2}$ year $\left.^{-1} \pm \mathrm{SD} 0.636\right)$ regionally on average, it showed opposite patterns to that of the LST trend. In other words, the LE trend increased $\left(0.519 \mathrm{Wm}^{-2}\right.$ year $\left.^{-1} \pm \mathrm{SD} 0.469\right)$ in areas of significant LST cooling and decreased $\left(-0.173 \mathrm{Wm}^{-2}\right.$ year $^{-1} \pm$ SD 0.455$)$ in areas of LST warming (Fig. 7a, b). 


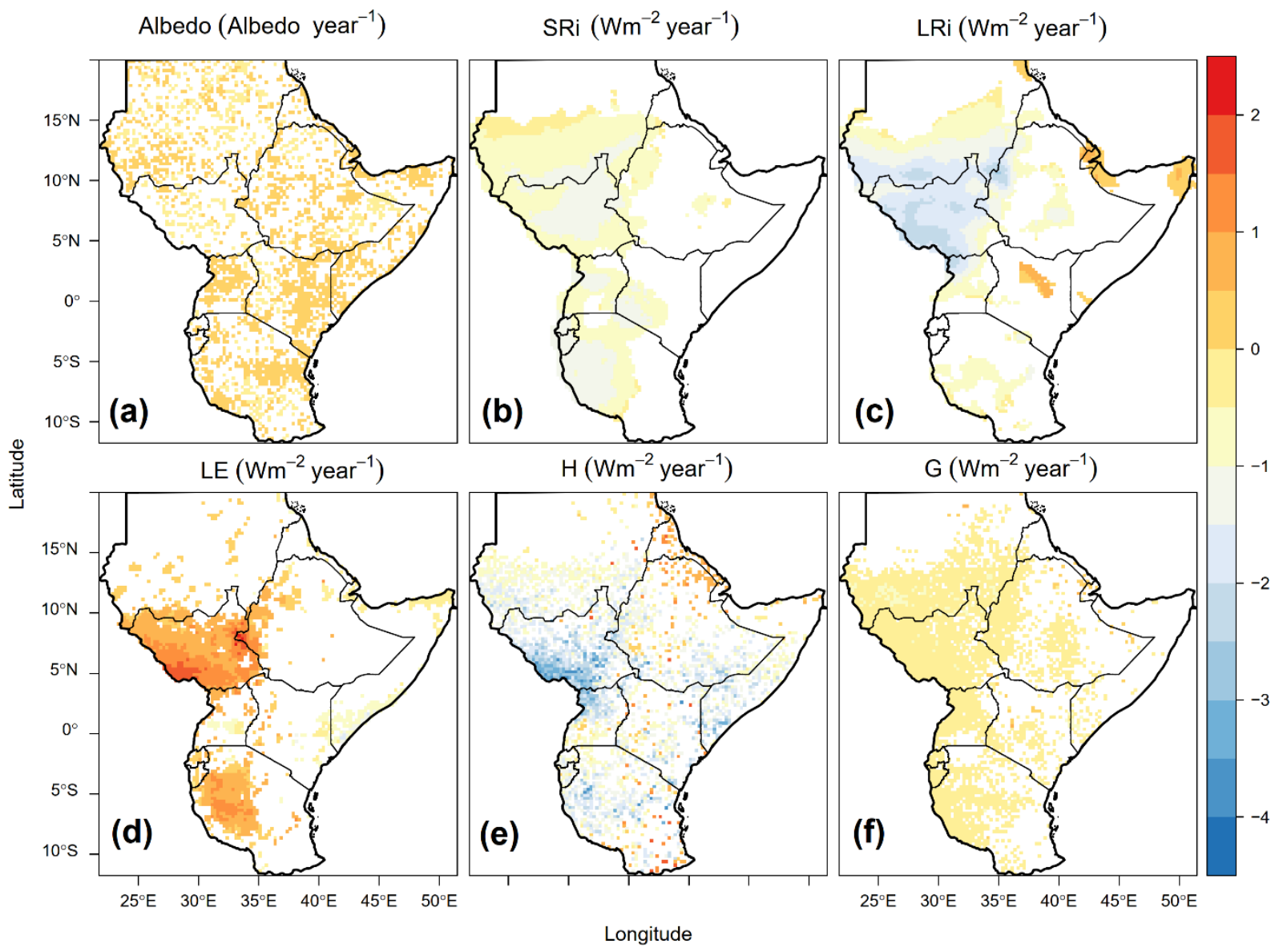

Figure 6. Trends of a) albedo, b) shortwave incoming radiation (SRi), c) longwave incoming radiation (LRi), d) latent heat flux (LE), e) sensible heat flux $(\mathrm{H})$, and $\mathrm{f}$ ) ground heat flux during 2003-2018. Only significant $(P<0.05)$ trends are displayed at $0.25^{\circ}$ resolution.
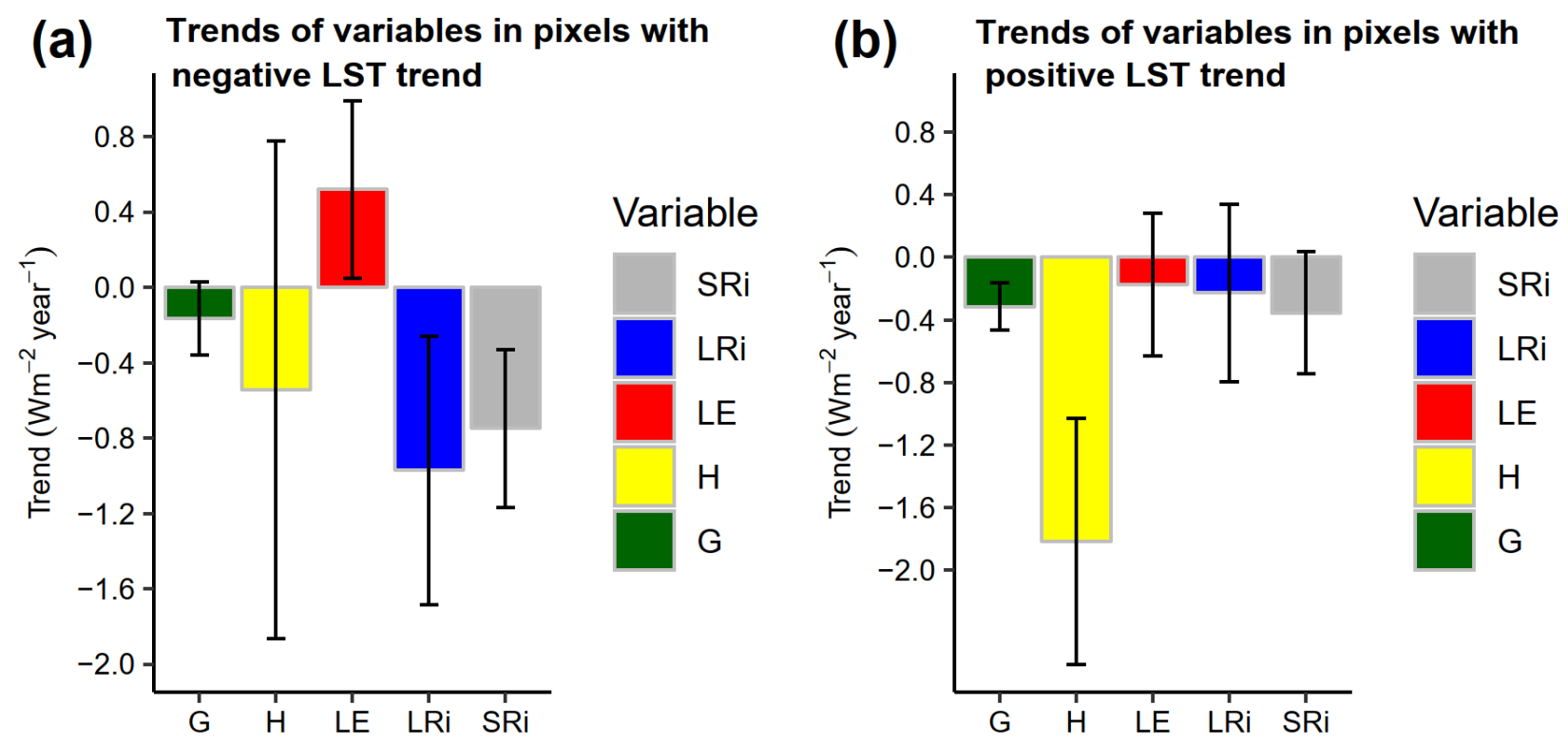

Figure 7. Trends of atmospheric and surface biophysical variables in areas of significant a) LST cooling trend and b) LST warming trend. The albedo trend is not displayed here due to negligible 
magnitude. $\mathrm{G}=$ ground heat flux; $\mathrm{H}=$ sensible heat flux; $\mathrm{LE}=$ latent heat flux; $\mathrm{LRi}=$ incoming longwave radiation; $\mathrm{SRi}=$ incoming shortwave radiation.

The impact on the LST trend depends on the sensitivity of LST to each of the surface biophysical and incoming radiation variables. Sensitivity was computed using Ordinary Least Square (OLS) regression after detrending the time series to avoid impacts of trend component on sensitivity term.

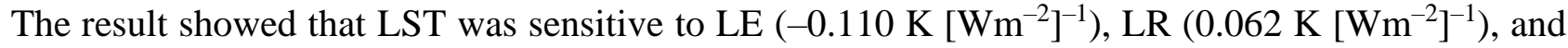

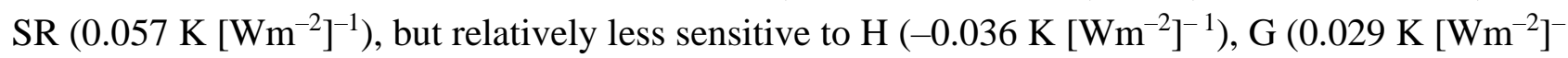
$\left.{ }^{1}\right)$, and albedo $\left(0.001 \mathrm{~K}\right.$ albedo $\left.^{-1}\right)$ (Fig. 8a-e).
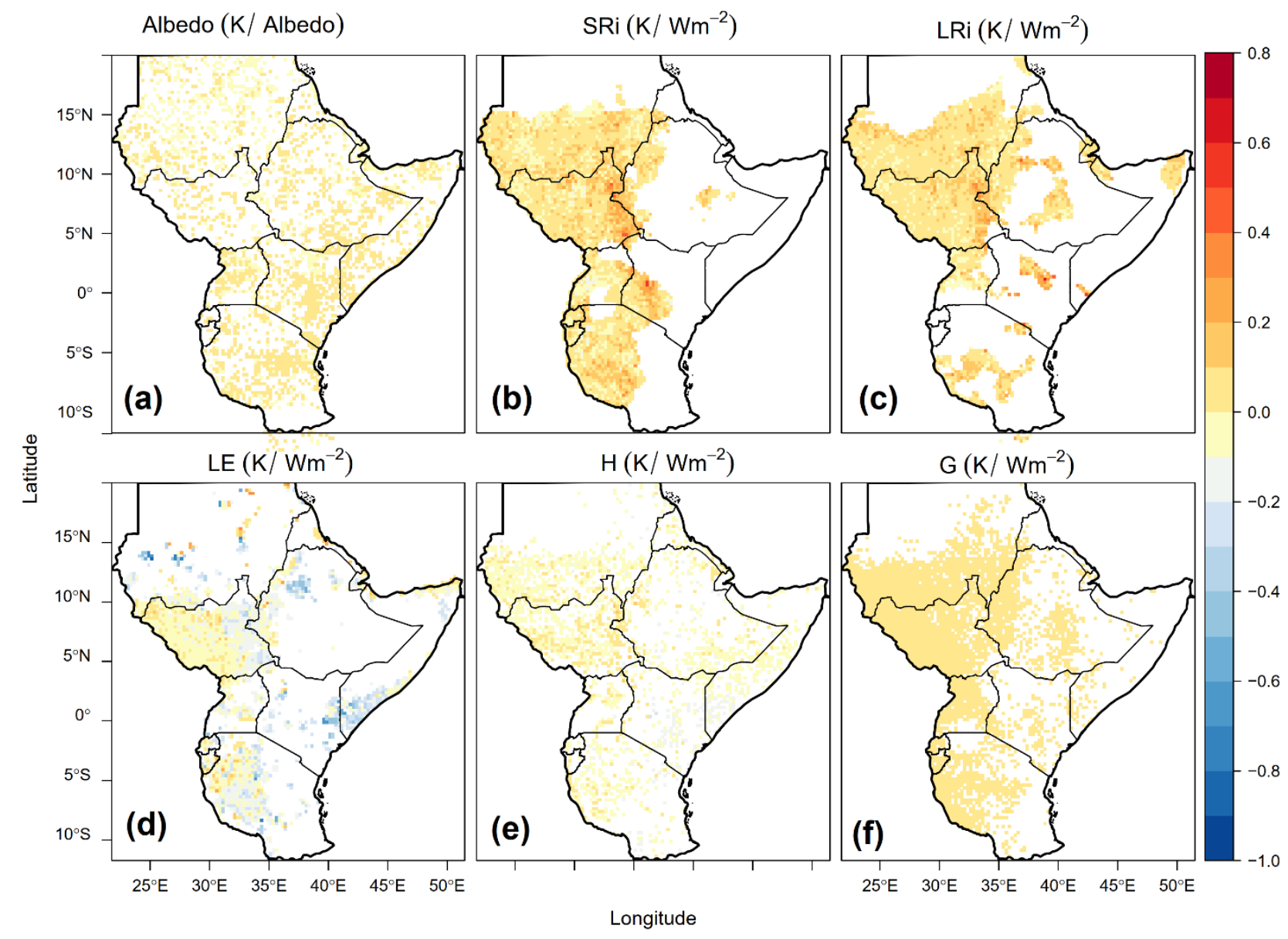

Figure 8. Sensitivity of surface temperature to a) albedo, b) incoming shortwave radiation, c) incoming longwave radiation, d) latent heat flux, e) sensible heat flux, and f) ground heat flux. Sensitivity is displayed for areas affected by significant $(P<0.05)$ trends as in Fig. 6 at $0.25^{\circ}$ resolution.

The spatial distribution of the contribution of each variable to the LST trend was inferred from the product of sensitivity term and trend (Fig. 9). Regionally, the cooling impact was dominant in terms of coverage. In areas of significant LST trend, the main contribution to LST cooling came from LR $\left(-0.167 \mathrm{~K} \mathrm{year}^{-1}\right.$, SD 0.092), LE ( $-0.151 \mathrm{~K} \mathrm{year}^{-1}$, SD 0.097), and SR ( $-0.149 \mathrm{~K}_{\text {year }}{ }^{-1}$, SD 0.092), while the contributions from $\mathrm{H}\left(-0.015 \mathrm{~K} \mathrm{year}^{-1}\right.$, SD 0.07), albedo ( $-0.007 \mathrm{~K} \mathrm{year}^{-1}$, SD 0.004$)$, and $\mathrm{G}\left(-0.003 \mathrm{~K}_{\text {year }}{ }^{-1}\right.$, SD 0.008$)$ were minor on average (Fig. 10a, e, and f). On the other hand, the 
LST warming was mainly affected by LE $\left(0.163 \mathrm{~K}\right.$ year $^{-1}$, SD 0.121$)$ and $\mathrm{H}\left(0.155 \mathrm{~K}_{\text {year }}{ }^{-1}\right.$, SD 0.102 ) while atmospheric radiation (i.e., SR $0.053 \mathrm{Wm}^{-2}$, SD 0.042 , and LR $0.049 \mathrm{Wm}^{-2}, \mathrm{SD} 0.044$ ), $\mathrm{G}\left(-0.019 \mathrm{~K} \mathrm{year}^{-1}\right.$, SD 0.004), and albedo (0.001 K year ${ }^{-1}$, SD 0.009) had a negligible impact (Fig. $10 \mathrm{a}, \mathrm{b}, \mathrm{c}$, and $\mathrm{f})$.

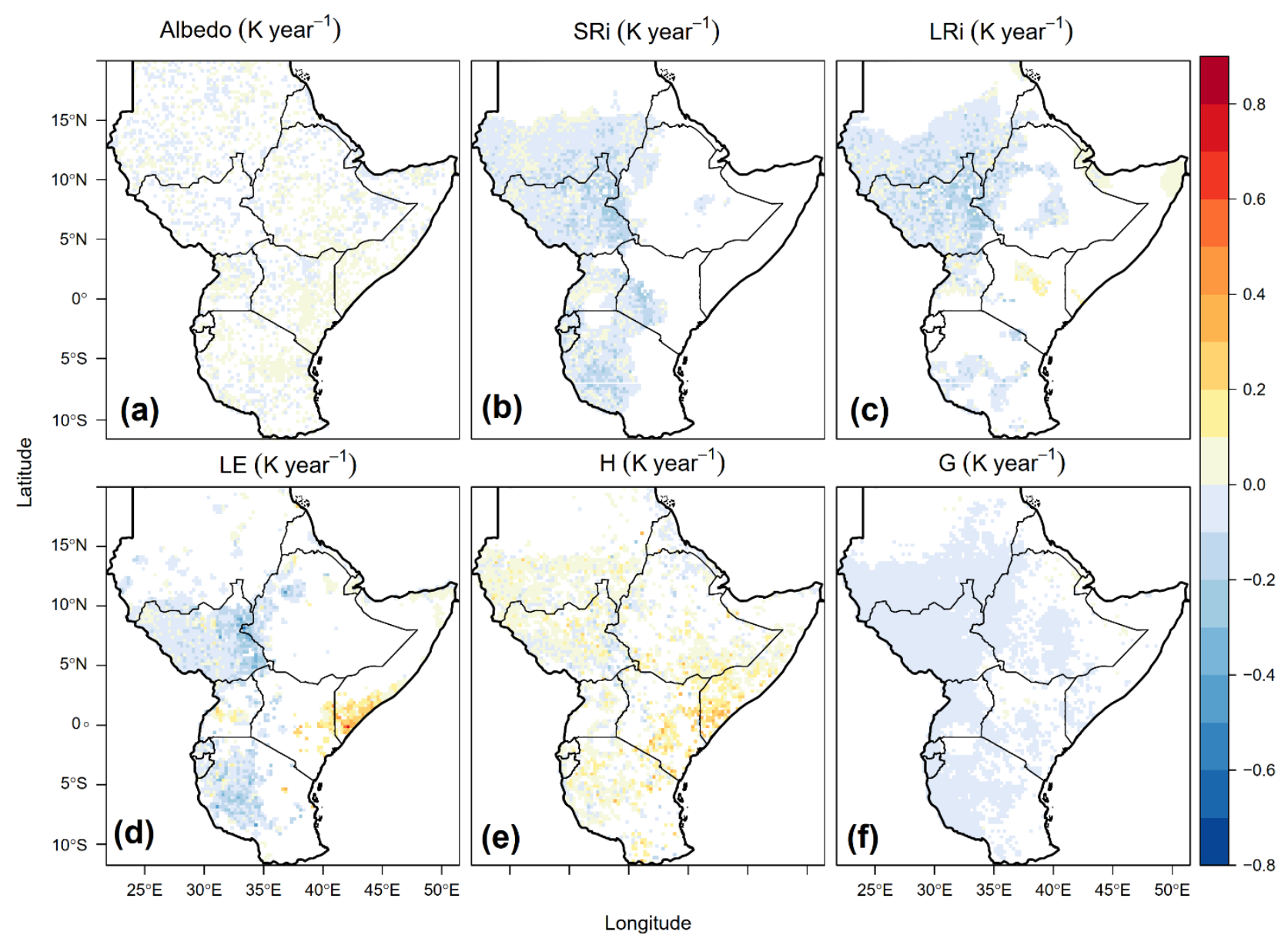

Figure 9. Impacts of atmospheric and surface biophysical variables (the product of sensitivity term and trend) on the magnitude of annual LST trend. SRi = incoming shortwave radiation; LRi = incoming longwave radiation; $\mathrm{LE}=$ latent heat flux; $\mathrm{H}=$ sensible heat flux; $\mathrm{G}=$ ground heat flux. 
(a) Contribution to LST cooling trend

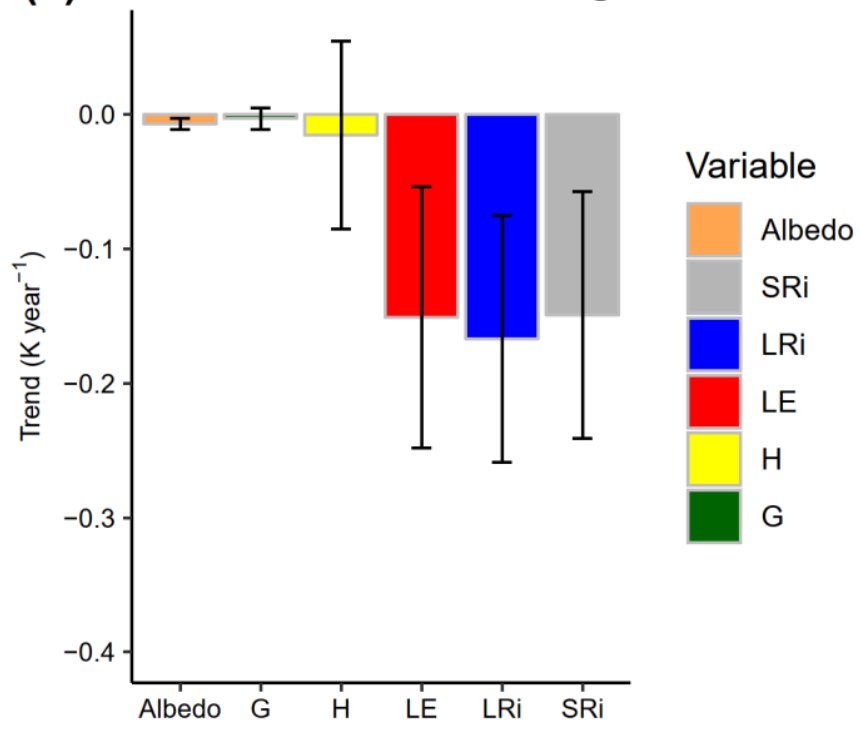

(b) Contribution to LST warming trend

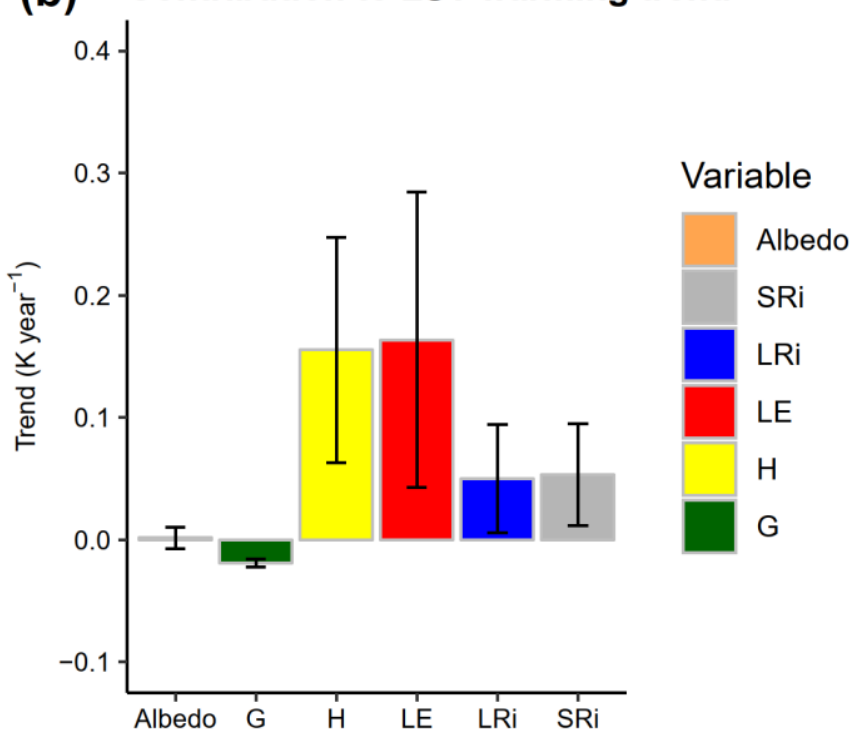

Figure 10. Contribution of atmospheric and surface biophysical variables in areas of significant a) LST cooling trend and b) LST warming trend. $\mathrm{G}=$ ground heat flux; $\mathrm{H}=$ sensible heat flux; $\mathrm{LE}=$ latent heat flux; $\mathrm{LRi}=$ incoming longwave radiation; $\mathrm{SRi}=$ incoming shortwave radiation.

The contribution of each variable to the overall LST trend (warming plus cooling) was estimated using the BRT model (Fig. 11). The albedo was removed from the model due to its negligible trend (Fig. 6a and Fig. 10a, b) and high standard error $(>4)$ unlike other variables (standard error $<0.01$ ). The model explained $88 \%$ of the total LST variance. Ground heat flux had minor changes and noncausal relation in areas of LST warming (i.e., G showed a small decrease in areas of increasing LST trend as indicated in Fig.10b) and hence was not considered in BRT to reduce model uncertainty. The most influential variables, in a decreasing order, were latent heat (31.6\%), incoming longwave radiation (29.7\%), incoming shortwave radiation (23.1\%), and sensible heat flux (15.6\%). Together, the atmospheric variables (LRi and SRi) explained only slightly more ( $53 \%)$ than the surface biophysical variables (47\%; $\mathrm{LE}$ and $\mathrm{H}$ ). 

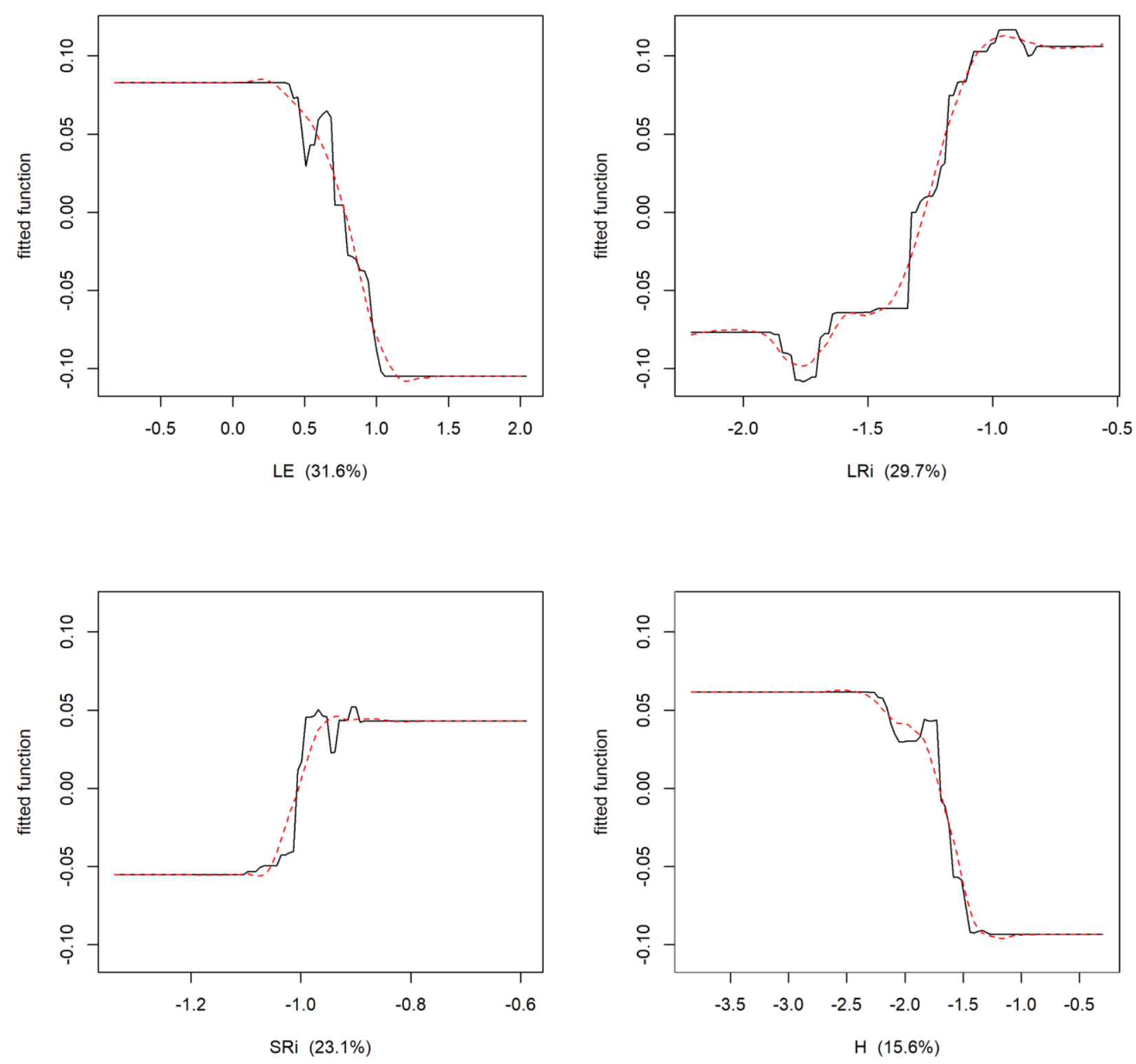

Figure 11. Partial-dependence plots and smoothed response curves for the explanatory variables in the $\mathrm{x}$-axis and response variable in the $\mathrm{y}$-axis (fitted function, LST trend) in the boosted regression tree model. Annual trends were used in all variables in the model. $\mathrm{SRi}=$ incoming shortwave radiation trend; $\mathrm{LRi}=$ incoming longwave radiation trend; $\mathrm{LE}=$ latent heat flux trend; and $\mathrm{H}=$ sensible heat flux trend. The relative contribution of each of the atmospheric and surface biophysical variables is shown in brackets in percentage. In total, the model explained $88.0 \%$ of the variance.

\section{Discussion}

Daytime LST trend showed both warming and cooling trends while the nighttime LST mainly diplayed a warming trend in EA. This pattern has reduced the trends of diurnal LST range in areas of divergent daytime (cooling) and nighttime (warming) LST trends. Our result showed that while both 
surface (increase in LE trend) and atmospheric (decrease in LRi and SRi) variables played an important role in daytime surface cooling, the surface warming was strongly influenced by surface variables. Below, the drivers of $\mathrm{LST}_{\text {day }}$ and $\mathrm{LST}_{\text {night }}$ trends as well as the limitations of our study are discussed.

\subsection{Surface biophysical drivers of LST trend}

An increase in LE reduces LST owing to the dissipation of energy from surface to the atmosphere through evapotranspiration (Zeng et al., 2017). The increase in latent heat flux shows strong spatial agreement with an increase in leaf area index (LAI) (Supplimentary Fig. S4). This indicates that the increase in latent heat flux can be associated with an enhanced surface greening. Previous global (Forzieri et al., 2017; Zhu et al., 2016) and sub-Saharan Africa (Martin et al., 2017) studies reported an increase in LAI trend and woody vegetation in EA using satellite observation data. Forzieri et al. (2017) further noted the surface cooling (i.e., LST reduction) in response to an increase in LAI in this region during 1982-2011. Based on modeling studies, Zeng et al. (2017) attributed an increased evapotranspiration as a major contributor to surface cooling related to global greening, including the Sahel region. Our result supports these studies and adds evidence from LE flux trend.

By contrast, a reduction in latent heat flux increases LST due to accumulation of energy on the surface as less energy leaves through evaporation. Similarly, the decrease in LAI closely matches with the reduction of latent heat flux indicating LAI control over the sign of LE flux trends in the region (Fig. S4). Nonethelss, the LAI trend solely can not fully explain the LE trend in the region (i.e., a regression between LE and LAI showed that LAI explains $42 \%$ of the LE variation). Soil evaporation trend, associated with climate extremes (e.g. drought events), can also affect the LE trend (Abera et al., 2020a). For instance, soil mositure trend explains $23 \%$ of the LE variation (see supplimentary Figure S5 and Table S1 for details), indicating impotant role of soil moisture. Other factors, such as global warming and anthropogenic activities (through land cover change) can also affect LE flux through their influence on evapotranspiration (Abera et al., 2019; Bright et al., 2017; Moratiel et al., 2010).

LE had the highest contribution (33\%) in explaining the overall daytime LST trends (warming and cooling). This is likely related to the stronger sensitivity of LST to LE flux in water-limited arid and semiarid environment (Fig. 8; Abera et al., 2020a; Small and Kurc, 2003) as well as due to the radiative heating of the surface, which is largely balanced by latent heat flux through evapotranspiration during daytime (Abera et al., 2019; Oke, 1987).

Sensible heat flux had minor impact on the total LST trend. This is attributed to the smaller influence of $\mathrm{H}$ on the LST cooling than LST warming. Meaning, in areas of surface cooling, the reduction of $\mathrm{SRi}, \mathrm{LRi}$, and LE decreases the difference in temperature between surface and air above and can lead to less convective transfer of energy from the surface to the atmosphere and can minimize the contribution of sensible heat trend. By contrast, the relatively higher contribution of $\mathrm{H}$ to surface warming can be explained by the strong declining trend in $\mathrm{H}$, which likely contributes more to LST warming as less energy leaves the surface to warm the air above.

The albedo trend had a negligible impact on LST trend. This result agrees with previous studies in tropical regions, which showed a minor role of albedo on the magnitude and sign of LST compared to LE (e.g., Abera et al., 2019; Li et al., 2016; Bright et al., 2017; Pielke et al., 1998). For example, an increase in albedo was reported in areas of increased LST during dry period in arid parts of EA 
(Abera et al., 2020a), indicating minor influence of albedo on LST since an increase in albedo is expected to reduce LST.

\subsection{Drivers of nighttime LST trends}

The increasing $\mathrm{LST}_{\text {night }}$ trend can be related to the enhanced LRi associated with the build-up of greenhouse gases in the atmosphere. LRi emission is the dominant process at night owing to the absence of shortwave radiation and consequent decline of surface biophysical processes (latent and sensible heat flux) (de Kok et al., 2020; Oke, 1987). On the other hand, the global warming effect is more pronounced at night than daytime due to higher sensitivity of nighttime air temperatue to perturbations of radiation balance associated with shallow boundary layer formation (Davy et al., 2016; Alexander et al., 2006; Vose et al., 2005). Thus, rapid warming of nighttime air temperature, in response to greenhouse gases effects, will likely increase LRi as warm air emits more longwave radiation. Especially, as the nighttime warming is weakly counterbalanced by biophysical processes, the greenhouse gas effect can be important in increasing LST trend through radiative warming. Overall, the result indicates that different mechanisms govern $\mathrm{LST}_{\text {day }}$ and $\mathrm{LST}_{\text {night }}$ trends.

\subsection{Radiative drivers of LST trend}

Although investigating the causes of SRi decline requires detailed analysis, two factors can be attributed to its reduction. First, scattering and absorbtion of solar radiation by aerosols (or direct radiative forcing) can reduce SRi (Lohmann, 2015). Analysis of Aerosol Optical Thickness (AOD) from MERRA showed a significant positive trend in the Sahel region (mainly Sudan and South Sudan) (Supplementary Fig. S6a) and the SRi reduction in the Sahel region can partly be related to aerosol increase. Furthermore, aerosol can also reduce SRi through indirect ways via its role in cloud condensation (or indirect radiative forcing) (Lohmann, 2015; Hansen et al., 1995).

Second, enhanced precipitation caused by factors other than aerosols (e.g., large scale climate oscillation) can reduce SRi through cloud scattering and absorption of SRi (Pfeifroth, 2018; Wild, 2016). Enhanced mean annual precipitation (MAP) was reported as main driver of increased LAI (or woody cover) in drylands of sub-Saharan Africa, despite its non-significant increase (Martin, et al., 2017). Analysis of precipitation data using TRMM showed similar indication of increasing MAP in small parts of Sudan and Uganda, although regionally, the trends were largely non-significant (Supplementary Fig. S6b). Hence, in those areas where MAP exhibited an increasing trend, the SRi could be affected.

The reduction of LRi affects the LST through its control on the transfer of thermal energy from the atmosphere to the earth's surface. The magnitude of LRi is affected by the outgoing LR from the earth. With a reduction in the SWi trend, less outgoing energy is expected to be emitted by the earth surface, which in turn can lead to a reduction in LRi during daytime. The decreasing trend in outgoing LR computed from CERES-EBAF product corroborates this explanation, mainly in South Sudan and Tanzania (Supplementary Fig. S7a).

However, other atmospheric conditions such as the concentration and vertical distributions of water vapor (Compo \& Sardeshmukh, 2009), cloud cover (Harrpor et al., 2016), carbon dioxide (Arrhenius, 1896), and trace gases (e.g., ozone, nitrous dioxide, methane, aerosols, etc.) can affect LRi (Liang et al., 2018). Furthermore, vegetation-climate feedback might affect the LRi through modifying the 
local air temperature via increased LAI in the region (Zeng et al., 2017). Hence, future studies are needed to clarify the influence of atmospheric and surface factors on LRi trends.

\subsection{Limitations and uncertainities}

Our results are limited to clear-sky observations. In other words, the results do not represent cloudy conditions and should be applicable for clear-sky conditions. The reason for restricting analysis to clear-sky observation was due to the high uncertainty and low accuracy of LST retrievals over pixels overcast by cloud. Furthermore, the inherent limitation of satellite observation and reanalysis data (e.g., accuracy and spatial resolution) can affect the results. For example, sensible heat flux, which was derived as residual of surface energy balance applying coarse resolution data, might carry large uncertainties as it contains errors from the surface energy balance closure. However, we have checked overall impact of satellite data uncertainties on closure of Eq.2 by comparing modeled LST trend, computed based on Eq. 2, with observed LST trend from MODIS. The result showed good agreement $\left(\mathrm{r}^{2}=0.82\right)$ (see supplementary Fig. S9 for details). However, dense networks of flux tower data are needed to independently verify and estimate the biases originated from satellite and reanalysis data on LST trend in data scarce region, such as East Africa in the future.

Also, the results of trend analysis might depend on the length of the data record used. Trends can change over time and space due to the dynamic nature of earth system processes. Our short term trend analysis (2003-2018) might not represent long term trends in climatological terms (30+ years) and the results should be used mainly for the mentioned period. However, the use of good quality LST retrievals along with the use of statistically significant trends of all variables in our analysis increases the robustness of the results.

The BRT model, which was based on explanatory variables selected from surface energy balance, was able to explain $88 \%$ of the LST trend. Thus, there are other factors unexplained by the BRT model (11\%), that can affect the LST trend. Land cover and management change is one such factor. Through anthropogenic modification of surface biophysical properties (e.g., LAI and associated evapotranspiration, surface roughness, and albedo, or through irrigation and application of fertilizers) land cover and management change can affect the water and energy fluxes between the land surface and the atmosphere (Pielke et al., 2007; Bright et al., 2017; Luyssaert et al., 2014) and hence LST trend. However, the anthropogenic impact can have more impact on the LST warming trend than cooling in the region due to widespread clearing of woody cover for agriculture in EA (Brink et al., 2014; Abera et al., 2019; Abera et al., 2020b). This indicates that increase in woody cover (e.g. through reforestation) can contribute in counteracting surface warming trend in the region (Abera et al., 2020b; Abera et al., 2019 ). The impacts of these and other possible factors were not addressed in our analysis. This, however, does not affect our conclusions as the BRT model mostly explained the LST trend in the region.

\section{Conclusions}

In this study, we assessed temporal trends in LST and its drivers across East Africa, applying satellite observation and reanalysis data during 2003-2018. Annual and seasonal trends of LST $_{\text {day }}, \mathrm{LST}_{\text {night}}$, and DSTR were explored. Surface (albedo, LE, and H) and atmospheric (SRi and LRi) drivers were 
analyzed to clarify their contribution to annual daytime LST trend based on surface energy balance and BRT model.

Significant trends in $\mathrm{LST}_{\text {night }}$ were observed in a larger portion of East Africa (31\%), in comparison with trends in $\mathrm{LST}_{\text {day }}(11 \%)$. $\mathrm{LST}_{\text {night }}$ trends (annually and seasonally) were dominantly positive (up to $99 \%)$, indicating an overal nighttime warming of $0.06 \mathrm{~K} \mathrm{year}^{-1}$, while both warming $\left(0.22 \mathrm{~K}_{\text {year }}\right.$ $\left.{ }^{1}\right)$ and cooling $\left(-0.19 \mathrm{~K}\right.$ year $\left.^{-1}\right)$ trends were prevalent during daytime. In terms of magnitude of change, the $\mathrm{LST}_{\text {day }}$ trends were up to $\sim 3$ times stronger than the $\mathrm{LST}_{\text {night }}$ trend. The DSTR showed a predominant (69\% in DJF to $88 \%$ in MAM) decreasing trend, affected by contrasting LST day $_{\text {and }}$ LST $_{\text {night }}$ trends. With the exception of the magnitudes, the spatial patterns between annual and seasonal trends were similar for each of the LST variants (i.e., $\mathrm{LST}_{\text {day }}, \mathrm{LST}_{\text {night, }}$, and DSTR).

Analysis of the annual LST drivers showed that both atmospheric (53\%) and surface (47\%) variables were important in explaining the overall LST trends. However, the impacts of these variables vary strongly in magnitude between areas affected by surface warming (i.e., largely dominated by LE and $\mathrm{H}$ ) and cooling (i.e., largely dominated by LRi, LE, and SRi) with the exception of LE, which had a crucial role in explaining both surface warming and cooling, and hence overall LST trend (32\%) in the region. LE flux trend closely mimics the leaf area index trend (i.e., greening and browning trend) and soil moisture trend, and both had significant $(P<0.05)$ impact on the observed LE trend in the region. Hence, we demonstrate that surface temperature trends over EA vary spatially and temporally, with different mechanisms governing these trends during daytime.

Overall, our results offer a new insight on how surface and atmospheric factors differently affect surface warming and cooling trends in EA, clarifying the drivers of LST trends, that can serve as an important input in earth system modelling and for monitoring of environmental changes in the region.

\section{Declaration of competing interests}

The authors declare no conflict of interest.

\section{Acknowledgement}

We acknowledge SMARTLAND (Environmental sensing of ecosystem services for developing climate smart landscape framework to improve food security in East Africa) project funded by the Academy of Finland (decision number 318645). Furthermore, Eduardo Maeda acknowledges funding from the Academy of Finland (decision numbers 318252 and 319905). We thank NASA for the provision of data used in this research. MODIS data (land surface temperature/emissivity, leaf area index, and albedo) and TRMM rainfall data were downloaded from https://lpdaac.usgs.gov/tools/earthdata-search/, NASA EOSDIS Land Processes Distributed Active Archive Center (LP DAAC), USGS/Earth Resources Observation and Science (EROS) Center, Sioux Falls, South Dakota. Upwelling longwave radiation data can be obtained from NASA at https://ceres.larc.nasa.gov/data/\#energy-balanced-and-filled-ebaf. MERRA-2 air temperature, aerosol optical depth, and incoming shortwave radiation data were obtained from NASA Goddard Earth Sciences (GES) Data and Information Services Center (DISC) at https://disc.gsfc.nasa.gov/datasets?keywords=\%22MERRA2\%22\&page $=1 \&$ source $=$ Models $\% 2$ FAnalyses $\% 20$ MERRA-2. 


\section{References}

Aalto, I. (2020). Assessing the cooling impact of tree canopies in an intensively modified tropical landscape. MSc thesis, University of Helsinki. http://urn.fi/URN:NBN:fi:hulib-202006233428

Abera, T.A., Heiskanen, J., Pellikka, P.K.E., Rautiainen, M., Maeda, E.E. (2019). Clarifying the role of radiative mechanisms in the spatio-temporal changes of land surface temperature across the Horn of Africa. Remote Sens. Environ., 221, 210-224. https://doi.org/10.1016/j.rse.2018.11.024

Abera, T.A., Heiskanen, J., Pellikka, P.K.E., Maeda, E.E. (2020a). Impact of rainfall extremes on energy exchange and surface temperature anomalies across biomes in the Horn of Africa. Agric. For. Meteorol., 280, 107779. https://doi.org/10.1016/j.agrformet.2019.107779

Abera, T.A., Heiskanen, J., Pellikka, P.K.E., Adhikari, H., Maeda, E.E. (2020b). Climatic impacts of bushland to cropland conversion in Eastern Africa. Sci. Total Environ., 717, 137255. https://doi.org/10.1016/j.scitotenv.2020.137255

Akinyemi, F.O., Ikanyengb, M., Muro, J. (2020). Land cover change effects on land surface temperature trends in an African urbanizing dryland region. City and Environment Interactions. 4, 100029. https://doi.org/10.1016/j.cacint.2020.100029

Alexander et al. (2006). Global observed changes in daily climate extremes of temperature and precipitation. J. Geophys. Res. Atmos., 111: D05109. https://doi.org/10.1029/2005JD006290

Aumann, H. H., Broberg, S., Manning, E., Pagano, T. (2019). Radiometric Stability Validation of 17 Years of AIRS Data Using Sea Surface Temperatures. Geophys. Res. Lett., 46(21), 12504-12510. https://doi.org/10.1029/2019GL085098

Bastiaanssen, W.G.M. (2000). SEBAL-based sensible and latent heat fluxes in the irrigated Gediz Basin, Turkey. J. Hydrol., 229 (1), 87-100, https://doi.org/10.1016/S0022-1694(99)00202-4

Bosilovich, M.G., Akella, S., Coy, L., Cullather, R., Draper, C., Gelaro, R., ..., Suarez, M. (2015). MERRA2: initial evaluation of the climate. Technical report series on global modeling and data assimilation. 43 (2015). https://gmao.gsfc.nasa.gov/pubs/docs/Bosilovich803.pdf

Bright, R.M., Davin, E.L., O'Halloran, T.L., Pongratz, J., Zhao, K., Cescatti, ～A. (2017). Local surface temperature response to land cover and management change driven by non-radiative processes. Nat. Clim. Chang., 7, 296-302. https://doi.org/10.1038/nclimate3250

Brink, A.B., Bodart, C., Brodsky, L., Defourney, P., Ernst, C., Donney, F. ..., Tuckova, K. (2014). Anthropogenic pressure in East Africa-Monitoring 20 years of land cover changes by means of medium resolution satellite data. INT J APPL EARTH OBS, 28 (1), 60-69. https://doi.org/10.1016/j.jag.2013.11.006

Cleugh, H.A., Leuning, R., Mu, Q., Running, S.W. (2007). Regional evaporation estimates from flux tower and MODIS satellite data. Remote Sens. Environ., $106(3), 285-304$. https://doi.org/10.1016/j.rse.2006.07.007

Compo, G. P., \& Sardeshmukh, P. D. (2009). Oceanic influences on recent continental warming. Clim. Dyn., 32(2), 333-342. https://doi.org/10.1007/s00382-008-0448-9

Davy, R., Esau, I., Chernokulsky, A., Outtena, S., and Zilitinkevich, S. (2017). Diurnal asymmetry to the observed global warming. Int. J. Climatol., 37, 79-93. https://doi.org/10.1002/joc.4688

de Kok, R.J., Steiner, F.J., Maxime Litt, M., Wagnon, P., Koch, I., Azam, M., Immerzeel, W.W.(2020). Measurements, models and drivers of incoming longwave radiation in the Himalaya. Int J Climatol., 40, 942-956. https://doi.org/10.1002/joc.6249

Dinku, et al. (2007). Validation of satellite rainfall products over East Africa's complex topography. Int. J. Remote Sens., 28, 1503-1526. https://doi.org/10.1080/01431160600954688

Donohoe, A., Armour, K. C., Pendergrass, A. G., \& Battisti, D. S. (2014). Shortwave and longwave radiative contributions to global warming under increasing CO2. PNAS., 111(47), 16700-16705. https://doi.org/10.1073/pnas.1412190111 
Elith, J.; Leathwick, J.R.; Hastie, T. (2008). A working guide to boosted regression trees. J. Anim. Ecol., 77, 802-813. https://doi.org/10.1111/j.1365-2656.2008.01390.x

Forzieri, G., Alkama, R., Miralles , D.G., Cescatti, A. (2017). Satellites reveal contrasting responses of regional climate to the widespread greening of Earth. Science. 356 (6343), 1180-1184. https://doi.org/ 10.1126/science.aal1727

Forzieri, G., Miralles, D.G., Ciais, P. et al. (2020). Increased control of vegetation on global terrestrial energy fluxes. Nat. Clim. Chang. 10, 356-362. https://doi.org/10.1038/s41558-020-0717-0

GCOS (2016). GCOS 2016 Implementation Plan. World Meteorological Agency (WMO). https://library.wmo.int/doc_num.php?explnum_id=3417. Accessed on 25 June 2020.

Graven et al. (2013). Enhanced Seasonal Exchange of CO2 by Northern Ecosystems Since 1960. Science. 341(6150), 1085-1089. https://doi.org/10.1126/science.1239207

Gueymard, A.C. and Yang, D. (2020). Worldwide validation of CAMS and MERRA-2 reanalysis aerosol optical depth products using 15 years of AERONET observations. Atmos. Environ. 225, 117216. https://doi.org/10.1016/j.atmosenv.2019.117216

Hansen, J., Sato, M., Ruedy, R. (1995). Long-term changes of the diurnal temperature cycle: implications about mechanisms of global climate change. Atmos. Res., 37 (1-3), 175-209. https://doi.org/10.1016/0169-8095(94)00077-Q

Harrop, B. E., and D. L. Hartmann (2016). The role of cloud radiative heating within the atmosphere on the high cloud amount and top-of-atmosphere cloud radiative effect. J. Adv. Model. Earth Syst., 8, 13911410. https://doi.org/10.1002/2016MS000670

Hijmans, R.J.; Phillips, S.J.; Leathwick, J.; Elith, J. Package 'dismo'. Available online: http://www12.frugalware.org/mirrors/cran.r-project.org/web/packages/dismo/dismo.pdf (accessed on 2 March 2020).

Hinkelman, L. M. (2019). The Global Radiative Energy Budget in MERRA and MERRA-2: Evaluation with Respect to CERES EBAF Data. J. Climate, 32, 1973-1994. https://doi.org/10.1175/JCLI-D-18-0445.1.

Indeje, M., and F. H. M. Semazzi (2000), Relationships between QBO in the lower equatorial stratospheric zonal winds and East African seasonal rainfall. Meteorog. Atmos. Phys., 73 (3-4), 227- 244. https://doi.org/10.1002/(SICI)1097-0088(200001)20:1\%3C19::AID-JOC449\%3E3.0.CO;2-0

Jin, M., Dickinson, R. E., (2010). Land surface skin temperature climatology: benefitting from the strengths of satellite observations. Environ. Res. Lett. 5 (4), 44004. https://doi.org/10.1088/1748-9326/5/4/044004

Juang, J., Katul, G., Siqueira, M., Stoy, P., Novick, K. (2007). Separating the effects of albedo from ecophysiological changes on surface temperature along a successional chronosequence in the southeastern United States. Geophys. Res. Lett., 34, 1-5. https://doi.org/10.1029/2007GL031296

Kato et al. (2018). Surface Irradiances of Edition 4.0 Clouds and the Earth's Radiant Energy System (CERES) Energy Balanced and Filled (EBAF) Data Product. J. Climate, 31, 45014527, https://doi.org/10.1175/JCLI-D-17-0523.1.

Kendall, M. G. (1975). Rank Correlation Methods. New York, NY: Oxford University Press.

Li, Z. L., Tang, B.H., Wu, H., Ren, H., Yan, G., Wan, Z., Trigo, I.F., Sobrino, J.A. (2013). Satellite-derived land surface temperature: Current status and perspectives. Remote Sens. Environ., 131, 14-37. https://doi.org/10.1016/j.rse.2012.12.008

Li, Y., Zhao, M., Motesharrei, S., Mu, Q., Kalnay, E., Li, S.(2015). Local cooling and warming effects of forests based on satellite observations. Nat. Commun., 6, 6603. https://doi.org/10.1038/ncomms7603

Liepert, B., Fabian, P., \& Grassl, H. (1994). Solar radiation in Germany-Observed trends and an assessment of their causes. Pt 1. Contributions to Atmospheric Physics, 67(1), 15-29. IAEA.

Liu, J., Schaaf, C., Strahler, A., Jiao, Z., Shuai, Y., Zhang, Q., ..., Dutton, E.G. (2009). Validation of moderate resolution imaging spectaroradiometer (MODIS) albedo retrieval algorithm: dependence of albedo on solar zenith angle. J. Geophys. Res., 114, 1-11. https://doi.org/10.1029/2008JD009969 
Lohmann, U. (2015). Aerosol-Cloud Interactions and Their Radiative Forcing. Reference Module in Earth Systems and Environmental Sciences. Encyclopedia of Atmospheric Sciences (Second Edition). Pages $17-22$.

Luyssaert et al. (2014). Land management and land-cover change have impacts of similar magnitude on surface temperature. Nat. Clim. Chang., 4, 389-393. https://doi.org/10.1038/nclimate2196

Mann, H. B. (1945). Nonparametric tests against trend. Econometrica 13, 245-259.

Me-ead, C., McNeil, R. (2019). Pattern and Trend of Night Land Surface Temperature in Africa. Sci. Rep., 9, 18302. https://doi.org/10.1038/s41598-019-54703-z

Moratiel, R., et al. (2010). Responses of Reference Evapotranspiration to Changes in Atmospheric Humidity and Air Temperature in Spain. Clim. Res., 44(1), 27-40. https://doi.org/10.3354/cr00919

Muroa, J., Straucha, A., Heinemann, S., Steinbach, S., Thonfeld, F., Waske, B., Bernd Diekkrüger, B., (2018). Land surface temperature trends as indicator of land use changes in wetlands. INT J APPL EARTH OBS., 70, 62-71. https://doi.org/10.1016/j.jag.2018.02.002

Nicholson, S.E. (2017). Climate and climatic variability of rainfall over eastern Africa. 55, 3, pp590-635. https://doi.org/10.1002/2016RG000544

Ogallo, L. J. (1988). Relationships between seasonal rainfall in East Africa and the Southern Oscillation. J. Climatol., 8(1), 31-43. https://doi.org/10.1002/joc.3370080104

Ohmura, A., \& Gilgen, H. (1993). Re-evaluation of the global energy balance. In G. A. McBean, \& M. Hantel (Eds.), Interactions between global climate subsystems the legacy of Hann. Washington, DC: American Geophysical Union.

Oke, T.R., Cleugh, H.A. (1987). Urban heat storage derived as energy balance residuals. Boundary-Layer Meteorol. 39, 233-245. https://doi.org/10.1007/BF00116120

Peñuelas, J., Rutishauser, T., \& Filella, I. (2009). Phenology Feedbacks on climate change. Science, 324, 887888. https://doi.org/10.1126/science.1173004

Pfeifroth, U., Sanchez-Lorenzo, A., ,Manara, V., ,Trentmann, J., Hollmann, R. (2018). Trends and Variability of Surface Solar Radiation in Europe Based On Surface- and Satellite-Based Data Records. J. Geophys. Res. Atmos., 123(3), 1735-1754. https://doi.org/10.1002/2017JD027418

Pielke Sr., R.A. Avissar, R., Raupach, M., Dolman, A.J., Zeng, X., Denning, A.S. (1998). Interactions between the atmosphere and terrestrial ecosystems: influence on weather and climate. Glob. Chang. Biol., 4 (5), 461-475. https://doi.org/10.1046/j.1365-2486.1998.t01-1-00176.x

Prigent, C., Jimenez, C., Aires, F. (2016). Toward "all weather," long record, and real-time land surface temperature retrievals from microwave satellite observations. J. Geophys. Res. Atmos., 121(10), 56995717. https://doi.org/10.1002/2015JD024402

Running, S., Mu, Q. Zhao, M., (2017). MOD16A2 MODIS/Terra Net Evapotranspiration 8-Day L4 Global $500 \mathrm{~m}$ SIN Grid V006. NASA EOSDIS Land Processes DAAC. https://doi.org/10.5067/MODIS/MOD16A2.006

Ruzmaikin, A., Aumann, H. H., Lee, J., Susskind, J. (2017). Diurnal Cycle Variability of Surface Temperature Inferred From AIRS Data. J. Geophys. Res. Atmos., 122(20), 10,928-10,938. https://doi.org/10.1002/2016JD026265

Schaaf, C. and Wang, Z. (2015). MCD43C4 MODIS/Terra+Aqua BRDF/Albedo Nadir BRDF-Adjusted Ref Daily L3 Global 0.05Deg CMG V006. NASA EOSDIS Land Processes DAAC. Accessed 2020-09-05 from https://doi.org/10.5067/MODIS/MCD43C4.006

Schmugge, T. J. and Becker, F. (1991). Remote Sensing Observations for the Monitoring of Land-Surface Fluxes and Water Budgets. In: Schmugge T.J., André JC. (eds). Land Surface Evaporation. Springer, New York, NY.

Sharifnezhadazizi, Z., H. Norouzi, S. Prakash, C. Beale, and R. Khanbilvardi (2019). A Global Analysis of Land Surface Temperature Diurnal Cycle Using MODIS Observations. J. Appl. Meteor. Climatol., 58, 1279-1291. https://doi.org/10.1175/JAMC-D-18-0256.1 
Small, E.E., Kurc, S.A. (2003). Tight coupling between soil moisture and the surface radiation budget in semiarid environments: implications for land-atmosphere interactions. Water Resour. Res., 39, p. 1278.

Smith, D., Mutlow, C., Delderfield, J., Watkins, B., and Mason, G. (2012). ATSR infrared radiometric calibration and in-orbit performance. Remote Sens. Environ., 116, 4-16. https://doi.org/10.1016/j.rse.2011.01.027

Stephens, G. L., \&Webster, P. J. (1981). Clouds and climate: Sensitivity of simple systems. J ATMOS SCI, 38(2), 235-247. https://doi.org/10.1175/1520-0469(1981)038<0235:CACSOS >2.0.CO;2

Stettz S., Zaitchik, B.F., Ademe, D., Musie, S., Simane, B. (2019). Estimating variability in downwelling surface shortwave radiation in a tropical highland environment. PLoS ONE 14(2): e0211220. https://doi.org/10.1371/journal.pone.0211220

Sun, D., and Pinker, R. T. (2004). Case Study of Soil Moisture Effect on Land Surface Temperature Retrieval. IEEE Geosci. Remote. Sens. Lett., 1(2), 127. https://doi.org/10.1109/LGRS.2004.824749.

Vose RS, Easterling DR, Gleason B. (2005). Maximum and minimum temperature trends for the globe: an update through 2004. Geophys. Res. Lett. 32: L23822. https://doi.org/10.1029/2005GL024379

Wan, Z., Zhang, Y., Zhang, Q., Zhang, Q., Li, Z.L. (2004). Quality assessment and validation of the MODIS global land surface temperature. INT. J. REMOTE SENSING. 25(1), 261-274. https://doi.org/10.1080/0143116031000116417

Wan, Z., Zhang, Y., Zhang, Q., Li., Z. (2002). Validation of the land surface temperature products retrieved from Terra Moderate Resolution Imaging Spectroradiometer data. Remote Sens. Environ., 83 (1), 163 180. https://doi.org/10.1016/S0034-4257(02)00093-7

Wan, Z., Hook, S., Hulley, G. (2015). MOD11A2 MODIS/Terra Land Surface Temperature/Emissivity 8Day L3 Global 1km SIN Grid V006. NASA EOSDIS LP DAAC. https://doi.org/10.5067/MODIS/MYD11A2.006

Wild, M. (2016). Decadal changes in radiative fluxes at land and ocean surfaces and their relevance for global warming. Wiley Interdiscip. Rev. Clim. Change., 7(1), 91- 107. https://doi.org/10.1002/wcc.372

Wilcox, R. (1998). A Note on the Theil-Sen Regression Estimator When the Regressor Is Random and the Error Term Is Heteroscedastic. BIOMETRICAL J., 40(3), 261-268. https://doi.org/10.1002/(SICI)15214036(199807)40:3\%3C261::AID-BIMJ261\%3E3.0.CO;2-V

Wild, M., Folini, D., Hakuba, M. Z., Schär, C., Seneviratne, S. I., Kato, S., ... König-Langlo, G. (2014). The energy balance over land and oceans: An assessment based on direct observations and CMIP5 climate models. Clim. Dyn., 44(11-12), 3393-3429. https://doi.org/10.1007/s00382-014-2430-z

$\mathrm{Xu}$ et al. (2018). Analysis of global LAI/FPAR products from VIIRS and MODIS sensors for spatio-temporal consistency and uncertainty from 2012-2016. Forests, 9(2), 73. https://doi.org/10.3390/f9020073

Yu, Y.; Privette, J.L.; Pinheiro, A.C. (2008). Evaluation of Split-Window Land Surface Temperature Algorithms for Generating Climate Data Records. Geosci. IEEE Trans Remote Sens.,46, 179-192. https://doi.org/10.1109/TGRS.2007.909097

Zeng, Z., Piao, S., Li, L. et al. (2017). Climate mitigation from vegetation biophysical feedbacks during the past three decades. Nat. Clim. Chang., 7, 432-436. https://doi.org/10.1038/nclimate3299

Zhu, Z., Piao, S., Myneni, R. et al. (2016). Greening of the Earth and its drivers. Nat. Clim. Chang., 6, 791795. https://doi.org/10.1038/nclimate3004 
